\title{
Using Decision Support System to Enable Crowd Identify Neighborhood Issues and Its Solutions for Policy Makers: An Online Experiment at Kabul Municipal Level
}

\author{
Jawad Haqbeen ${ }^{1, *(\mathbb{D})}$, Sofia Sahab ${ }^{2}$, Takayuki Ito $^{2}$ and Paola Rizzi ${ }^{3}$ \\ 1 Department of Computer Science, Nagoya Institute of Technology, Nagoya 466-8555, Japan \\ 2 Department of Social Informatics, Kyoto University, Kyoto 606-8501, Japan; sahab.sofia@nitech.ac.jp (S.S.); \\ ito@i.kyoto-u.ac.jp (T.I.) \\ 3 Department of Architecture, Design and Urban Planning, University of Sassari, 07100 Sassari, Italy; \\ rizzi@uniss.it \\ * Correspondence: jawad.haqbeen@itolab.nitech.ac.jp
}

\section{check for} updates

Citation: Haqbeen, J.; Sahab, S.; Ito, T.; Rizzi, P. Using Decision Support System to Enable Crowd Identify Neighborhood Issues and Its Solutions for Policy Makers: An Online Experiment at Kabul Municipal Level. Sustainability 2021, 13, 5453. https://doi.org/10.3390/ su13105453

Academic Editors: Paola Di Biagi, Sara Basso and Alessandra Marin

Received: 22 March 2021

Accepted: 10 May 2021

Published: 13 May 2021

Publisher's Note: MDPI stays neutral with regard to jurisdictional claims in published maps and institutional affiliations.

Copyright: (c) 2021 by the authors. Licensee MDPI, Basel, Switzerland. This article is an open access article distributed under the terms and conditions of the Creative Commons Attribution (CC BY) license (https:/ / creativecommons.org/licenses/by/ $4.0 /)$.

\begin{abstract}
Planning a city is a systematic process that includes time, space, and groups of people who must communicate. However, due to security problems in such war-ravaged countries as Afghanistan, the traditional forms of public participation in the planning process are untenable. In particular, due to gathering space difficulties and culture issues in Afghanistan, women and religious minorities are restricted from joining male-dominated powerholders' face-to-face meetings which are nearly always held in fixed places called masjids (religious buildings). Furthermore, conducting such discussions with human facilitation biases the generation of citizen decisions that stimulates an atmosphere of confrontation, causing another decision problem for urban policy-making institutions. Therefore, it is critical to find approaches that not only securely revolutionize participative processes but also provide meaningful and equal public consultation to support interactions among stakeholders to solve their shared problems together. Toward this end, we propose a joint research program, namely, crowd-based communicative and deliberative e-planning (CCDP), a blended approach, which is a mixture of using an artificial-intelligence-led technology, decision-support system called D-Agree and experimental participatory planning in Kabul, Afghanistan. For the sake of real-world implementation, Nagoya Institute of Technology (Japan) and Kabul Municipality (Afghanistan) have formed a novel developed and developing world partnership by using our proposed methodology as an emerging-deliberation mechanism to reframe public participation in urban planning processes. In the proposed program, Kabul municipality agreed to use our methodology when Kabul city needs to make a plan with people. This digital field study presents the first practical example of using online decision support systems in the context of the neighborhood functions of Gozars, which are Kabul's social and spatial urban units. The main objective was to harness the wisdom of the crowd to innovative suggestions for helping policymakers making strategic development plans for Gozars using open call ideas, and for responding to equal participation and consultation needs, specifically for women and minorities. This article presents valuable insights into the benefits of this combined approach as blended experience for societies and cities that are suffering long-term distress. This initiative has influenced other local Afghan governments, including the cities of Kandahar and Herat as well as the country's central government's ministry of urban planning and land, which has officially expressed its intention to collaborate with us.
\end{abstract}

Keywords: bottom-up practices; e-participation; collective intelligence; neighborhood functions; artificial intelligence; consensus building; strategic urban planning; decision-support system; crowdsourcing; collective agreement 


\section{Introduction}

Civic engagement, which must include its citizenry in societal activities and processes, is a critical component in the successful implementation of any plan [1,2]. Civic engagement consists of interest, knowledge, discussion, and participation elements in activities and processes [3]. Discussions without knowledge or interest are meaningless, and participation without discussion is passive [4]. These four elements are required to maintain a widely accepted community participation. In addition, planning a city requires civic engagement that includes time, space, and people who communicate to identify innovative solutions and reach conclusions [5]. The main objective of civic engagement is to fuel public affairs and policy issues related to a community. Thus, discussion is the key element within participation; without active discussion, genuine participation cannot be maintained [3]. The public's inclusion is also critical in forging sustainable policies and developing a smart society [6] because development actions often fail without the participation of citizens [7]. Public participation based on discussion promotes quality solutions through reasoning and improves planning outcomes [8]. Participatory planning, which is of central interest in urban development [9], is required to prevent conflicts by providing a broad acceptance of plans [10].

As described in 1969 by Sherry Arnstein, at the bottom rung of her proposed ladder, participation exists in an entirely passive movement without interaction among stakeholders; full interactivity exists at the top when public officials and citizens completely engage with each other [4]. Her proposed planning method has shaped policies affecting the growth and changes in participatory methods. Because urban planning needs a structural transformation in its hierarchical model, it moved toward a reticular model that allows meaningful input from every stakeholder [11]. Thus, the participatory-planning paradigm emphasizes planning with people to harmonize views among all stakeholders [12]. Other work extended participatory planning and added such terms as communicative planning with people [13,14], deliberative planning [15], and planning through public consensus building [16].

Participatory planning [17] incorporates more public participation in decision-making processes. However, due to time, space, and gender restraints [18] as well as security issues [19], most people cannot participate in consultation and planning processes, and implementing bottom-up participation theories is difficult, especially in war-ravaged countries like Afghanistan. For example, challenges remain: achieving four critical civic engagement elements [3] mentioned before; two public participation factors: (1) each citizen must have access to information related to the planning process and activities, and (2) decisions concerning urban issues must be made after a consensus between a city and its citizens [20,21]; these four principles of participation must be ensured: (1) inclusivity, (2) transparency, (3) interactivity, and (4) continuity [22].

Researchers have been inspired by recent trends in information communication technologies (ICTs), which are analogous to Arnstein's ladder of citizen participation [4], and a new topology has been adopted to reframe participatory planning as participatory eparticipation and planning [23]. Participatory e-planning resembles e-participation using online participative methodologies $[24,25]$ to empower citizens to climb the participation rungs in urban policy processes without time or space limits [26-28]. However, researchers argue that a publicly virtual presence without supportive means through online social platforms alone cannot guarantee meaningful discussions and consultations because it fails to provide such (1) supportive means to facilitate a fair reasoning process among all stakeholders [29] or (2) incentive mechanisms required to stimulate efficient communication and collaboration among users [30]. For example, Facebook does not provide support to facilitate, extract, and converge discussions for building a consensus in real-time [31]. These lines of communication often involve discussion in an atmosphere of confrontation that can discourage interaction at scale for the social good [32]. Furthermore, the insights from these platforms cannot be used because policymakers might face a decision problem while integrating the unstructured voices of citizens collected through such platforms [3]. 
Some research argues that forums must provide supportive means like automated facilitation [30,33], discussion annotation [33,34], incentivized discussions [35,36], real-time visualization [34], and the involvement of every stakeholder to actively seek community input on planning issues and proper responses by linking processes to action [37,38]. In this background, online discussion and decision platforms based on supportive means are attracting great attention as approaches that overcome these shortcomings-if properly deployed in collaboration with local governments $[12,24,25,39]$. These systems might be used as a sustainable complement $[40,41]$ to support traditional participatory methods and tools $[42,43]$ by removing the inequalities of access information and participatory mechanism [44], engaging crowds and harnessing collective intelligence [39,45,46], removing gender barriers to exceed collective intelligence [47], and establishing links between the collective participatory processes and actions [37].

Even though the literature discusses the efficiency of crowd consultation in planning theory with the support of online-discussion support forums, less attention is paid to how least developed countries (LDCs) (such as Afghanistan) cope with budgetary restraints as well as issues of space, security, and gender. How are these countries simultaneously promising to increase community participation and to understand the planning using online tools to communicate in their societies while also increasing the interaction between public officials and their citizens at scale [48-50]? This is because, due to the atmosphere of confrontation in war-ravaged countries like Afghanistan, enacting bottom-up participation theory without the support of decision systems is complicated [3]. As a result, participatory planning at scale remains unavailable in decision-making processes.

Toward that end, this paper reports a novel element of a developed and developing world partnership and proposes an emerging deliberation mechanism by combining AI and experimental participatory planning to reframe public innovative participation in urban planning process to increase the civic engagement elements [3], factors [20] and principles [22] mentioned above. Furthermore, harnessing the collective intelligence or wisdom of crowds based on consensus approaches by implementing crowdsourcing with the support of AI technology within an urban planning process helps policymakers understand organized public needs and suggestions [3]. To the best of our knowledge, this is the first effective practical example that shows how LDCs can increase community participation by focusing on listening to citizens' suggestions, problems and needs using an AI-enabled participative platform.

Our project is part of a much wider statutory process of participation that involves the Kabul municipality (KM) and its citizens for discussions at the neighborhood and city levels. Most in-person public participation schemes have been relatively temporary [3]. In contrast, we regard our participation project as a permanent or a long-term participation process. After 18 months, our project's e-community members increased to over 12000 Afghan citizens (female $=16.9 \%$ and male $=83.1 \%$ ), and we have conducted 119 large-scale online discussions in collaboration with KM.

Note that in this paper, we do not present all of our experiments. Its scope is focused on presenting a joint research initiative and the result of one pilot case experiment on Gozars. It serves as a good practice example for involving Gozar people at scale and concentrating on their suggestions, needs, and problems in relation to the functions of Gozars. Using Gozars as a case study, this paper shows how crowdsourcing with the support of AI technology can improve and create Gozar communicative planning. Our paper makes two contribution to the literature:

1. We propose a novel partnership between a developed country (Japan) and a developing country (Afghanistan) using a platform centered around a conversational agent that uses AI technologies to interact, extract, visualize, and help people reach agreements in an urban development planning process.

2. We conducted a qualitative content analysis as a human-led study on four types of AI-led extracted social insights of experimental participatory planning to understand the chain of thought of Gozar residents and to draw meaningful conclusions. Our 
perspective is based on sharing the valuable catalogued insights of citizens with

Kabul city policymakers who must officially consider their insights while forging future, strategic policies for the Gozars.

The rest of the paper is structured as follows. A literature review is shown in Section 2, and its objective and methodology are shown in Section 3. Section 4 describes its experimental setting, and its results are discussed in Section 5. Finally, Section 6 presents a discussion, future work, and conclusions.

\section{Literature Review}

The following literature focuses on aspects that have direct relevance to the topic of local government use of online forums to promote civic engagement in urban development planning. We review research relating to how academia in collaboration with local governments are using online-discussion and decision-support tools to empower communities and to harness their intelligence for the social good.

\subsection{Strategic Urban Development Planning with People}

Strategic development planning with the public is a systematic process by which a community anticipates and plans for its future [51]. There were positive impactful outcomes from the participatory approaches [52].

The main outcome of a strategic planning process is a strategic development plan [3], which identifies critical, long-term priorities with the public as well as outcomes to be achieved by the municipality. This is a step we are taking in collaboration with local governments and presenting in this paper. A strategic plan is a basic conceptual and development document created by all of the engagement of the urban related stakeholders within a city [3]. Its main objective for involving all stakeholders, especially each citizen, is to develop a plan on the basis of balancing the interests of individual urban stakeholders and using everyone's insights within that plan.

In deliberative democracies, the first step in creating a solid plan is to open the lines of communication at scale [3]. The municipality staff, managers, and directors should engage and collaborate with citizens as much as possible to confirm that their suggestions and needs are obtained while verifying that the plan focuses on appropriate initiatives. Improving city-citizen collaboration is a crucial step in fostering transformative adaptation [53]. However, due to some constraints-particularly security because local governments in Afghanistan cannot manage a process that seeks bottom-up practicesalternative methods of participation that complement or replace traditional participatory methods and tools are needed [42].

\subsection{Civic Engagement with Support of Online Forums}

In town-related civic engagement, especially participatory-planning contexts, online technology "involves municipality-citizen relationship whereby a municipality executes a managed process that seeks the bottom-up, open, and creative input of citizen in an online community," and such management with the support of technology creates a productive process [54]. The term groupware was first coined in 1982 by Peter Johnson-Lenze and Trudy Johnson-Lenze $[55,56]$. They theorized that group work must be physical, but as an efficient complementary tool, groups can construct things in virtual structures using online forums. Some of the first forum systems include the planet-forum system (in the 1970s), EIES (1976), and KOM (1977). These three systems were among the very first computer systems that are today known as social computing, social networks, or online forums [57].

Although the internet was born in the United States in the 1960s for government and military researchers [16], its first commercialization operational in 1983 helped commercial online forums upgrade their environments from centralized time-sharing to distributed environments [16]. This evolution allowed the public to participate in almost instantaneous communication on a global scale. In every corner of the internet, people talk together using such services as blogs, social platforms, discussion forums, etc. An internet forum is a 
computer-mediated communication online-discussion site where people can hold conversations in the form of posted messages [16]. Distributed versions of online forums enable people to connect, communicate, and cooperate to solve problems in ways face-to-face meetings cannot [58]. However, due to the distributed and asynchronous nature of online communities and citizen-initiated platform usage, their collaboration and communication are often challenging [30]. Furthermore, one primary objective of such systems remained unknown, harvesting the collective intelligence of crowds and crowdsourcing at scale.

Toward that end, interest in "engaging the crowd" increased, and the objective was to identify innovative solutions to social issues [59]. Thus, the providers of crowd platforms and crowdsourcers have to consider both extrinsic and intrinsic motivations to facilitate collaboration among crowds [60]. In that background, the term collective intelligence was first coined by Thomas W. Malone at the MIT Center of Collective Intelligence [61]. He theorized that the businesses of the future will look very different because of collectiveinformation gathering. Malone subsequently argued that if groups of individuals collectively do tasks with the support of AI-involving machines, such collaboration will produce a collective intelligence that connects different types of individuals to produce a body of knowledge [45,62].

The term crowdsourcing was coined by Jaff Howe in 2006 [46] who recognized a new source of cheap labor in online communities that use their spare cycles to create content using online forums to solve soft problems and promote research and development through generated content. Howe believed that crowdsourcing resembled an institution taking a function previously performed by employees and outsourcing it to an undefined network of people as open calls. The open-call idea might be unified as an invitation for anyone to participate in online tasks by contributing information or knowledge [54].

According to Daren C. Brabham [54], crowdsourcing is the main mechanism for harnessing collective intelligence with the support of online forums and AI technology [63]. Crowdsourcing mainly identifies four specific tasks: (1) knowledge discovery, which collects knowledge reported by online communities; (2) distributed human intelligence tasking, which distributes "microtasks," the required human intelligence to be solved online in discussion support forums; (3) broadcast searches, which widely distribute problem-solving challenges on the internet and reward solutions, such as NASA's prize for an algorithm that predicts solar flares; and (4) peer-vetted creative production, which makes such solutions where an online community both proposes possible solutions and is empowered to collectively choose among them. Brabham first argued that crowdsourcing might be effectively used in the public sector as a particular form of citizen participation in public policy processes [64]. Brabham believed that, in the context of participatory planning, crowdsourcing happens when (1) a municipality requires to make a plan; (2) it engages an online community with the support of online forums to harness the wisdom of citizens; and (3) the result mutually benefits both the city and its citizens. The most important elements include the intention of the municipality, the interests of the community, and the role of online forums as a crowd-sourcing enabler that serves as an intermediary online platform between a municipality and its citizens [65].

Various cities have addressed the using of online forums for public participation, consultation, and opinion gathering in urban planning. An online participation system was used in the Woodberry Down regeneration project in the United Kingdom [66] to collect citizen opinions in one of Europe's biggest regeneration projects. Another study [67] introduced an online-design collaboration system for public participation and experimented on planning and designing public parks in Japan. A similar study introduced an online-participation system that was applied to a railroad removal project in Korea [68]. In Indonesia, LAPOR, an online portal, gathered citizen opinions [69]. Another work [70] presented an e-participation tool that supported citizen e-participation in regional urban debates by gathering news and opinions published on the web for easy comprehension and commentary. An e-participatory system supported decision-making processes using virtual reality (VR) technology to visualize citizen-submitted proposals [71] to support 
decision-making by encouraging citizen involvement. However, online-discussion systems suffer from automated facilitation problems and lack a clear incentive mechanism to motivate involvement between cities and citizens. Most critically, some cannot support large-scale participation at the municipal level. A number of challenges remain, such as human biases and time restrictions that need to be solved in human-facilitator-based, online-discussion systems [72]. As a result, AI-enabled automated facilitation is required to overcome these shortcomings within large-scale online discussions [12].

\subsection{AI-Enabled Online Forum as Crowdsourcing Tool for Urban Planning}

AI-enabled, online-discussions support the forums of automated discussion facilitation, visualization, and annotation in ways that traditional online forums and social networks cannot support [24,58,73]. These systems are appropriate models for enabling citizen-participation process in planning processes to help reach agreements and harness collective insights for both decision and policy making, e.g., [25,64,74]. These forums create equal opportunities for public participation [75,76], improve civic participation [77], and help reach appropriate decisions by collecting and sorting the suggestions and needs of people at scale $[34,63,72,78-80]$.

These forums are particularly suitable for urban planning because they voluntarily facilitate online communities to address their shared issues $[25,76,81]$. The adequately facilitated people who socialize at the place where they live can easily solve the soft problems that affect them better than anyone who is outside the community [64]. Such citizens are more aware of the problems in their neighborhood, and their proposed suggestions will be more widely accepted by future citizens [82]. Using these technologies in collaboration with local government leads to "greater legitimization and acceptance of public decision, greater transparency, efficiency in public expenditures and grater citizen satisfaction" [62,82]. Societies are pluralist, and legitimate conflicts of interest must be addressed by applying a discussion-based consensus-building method. Participatory planning that includes all the urban stakeholders and their varied interests and backgrounds makes a plan that is comprehensive, acceptable, and more easily implementable [2]. With these traits in mind, participatory e-planning, based on the support of participative platforms and facilitation, has the potential to involve large-scale, diverse groups of people in planning dialogues and to effect powerful civic engagement by introducing more solutions and suggestions to the planning [83] and by annotating discussion elements and extracting real insights help the policy makers $[34,35]$.

Using AI-enabled crowd discussions support systems in planning processes makes it possible to collect the suggestions of crowds and take appropriate decisions based on the overall real insights [84]. This explains why many cities actively seek new methods, such as Web 2.0 applications [85], with the support of mobile or desktop applications [86], social computational platforms [87], online-discussion support platforms [24], citizen's online consultation and participatory platforms [74] to engage their citizenry in the urban planning process [88].

Various cities have used AI-enabled crowd discussion tools for public participation and opinion collection in urban planning. For example, an online-discussion platform, COLLAGREE [24], collected opinions from citizens for next-generation city planning in collaboration with the Nagoya City Municipality, Japan [25,81]. Its objective was citizen engagement and using the gathered opinions and extracted insights for Nagoya's nextgeneration city policymaking [24].

Using a discussion and decision support system with the support of AI facilitation is an emerging deliberative democratic means of encouraging people to participate in municipal urban planning to promote communicative planning with civic engagement at scale and harnessing collective intelligence for creating better policies [89]. Crowdsourcing with the support of AI technology in urban planning can thus be seen as one of the latest so-called deliberative democratic innovations, designed to deepen participation-based discussions in urban process and effectively solve soft urban issues [76,90]. In this study, 
the crowd is invited by its municipality to submit opinions to discuss issues they face with them [76]. This input is artificially facilitated using AI, and then it is annotated and visualized the discussion components as Issues, Ideas and Pros and Cons as a discussion tree using a discussion structure called IBIS [74] to fuel reasoning processes and support collective agreement by developing argumentation and ideation. The extracted insights might help policymakers make efficient decisions, which are then incorporated (as needed) into strategic-planning processes [91]. If implemented on a national scale, this method can ameliorate many of the difficulties in participatory planning and bring solutions to urban problems by helping policymakers take appropriate decisions at the municipal level [76].

\subsection{Benefits of AI-Enabled Online Forum for Municipality}

Some argue that online forums with the support of AI technology are an appropriate model that enables participation and harnesses the collective intelligence of crowds for urban policymaking $[25,81]$. AI-enabled online forums with crowdsourcing capabilities provide municipalities with an opportunity to reach more citizens [92] and capitalize on their knowledge to develop innovative solutions to societal problems $[62,64,74]$ by reducing municipal administration costs [93,94], helping policymakers create more realistic policies [95], and securely revolutionizing engagement. Such forums also promote transparency and accountability and reduce planning corruption, all of which are critical for a country like Afghanistan [95].

With support of AI technology, this method allows citizens to influence the topics that are included in urban planning agendas [93] to introduce a new form of community building for municipalities [96] and build social capital [97]. AI-enabled online forums increase all four elements [3], two factors [20,21] and the four principles [4] of citizen engagement mentioned above in the introduction part and provide a bridge between municipalities and citizens to build sustainable cities with the power of crowd insights $[95,98]$. Using this methodology, crowd might be collectively engaged to work collaboratively in order to offer innovative solutions based on collective agreements, which might improve cities in line with the sustainable development goals of the United Nations (SDG-11 13).

\section{Objectives and Methods}

The objective of this article is to describe the process of a joint research initiative program that inspired a local government to use an online-discussion, decision-based support system as a tool for a strategic urban development plan-creating process at the Kabul city municipal level. As a first pilot and case study, we used our tool to enable crowd identification within a specific case of Kabul Gozar issues for strategic planning. Our research's general methodology conducts experimental participatory planning on behalf of a municipality with an online-discussion, decision-support system based on conversational agents and human experts as facilitators who encourage citizen participants to engage in themed discussions. Citizens may then join them based on their individual preferences [99]. We used convenience sampling [100] to collect a large sample size. Thus, online open-call [54] links were widely disseminated, and anyone interested was allowed to join the discussions.

We conducted a qualitative content analysis over the machine-extracted insights of participants in a human-led study to understand the chain of citizen thoughts related to Gozar functions. We also compared a part of this research with the results of our questionnaire surveys conducted on Gozars in 2013 [101].

\subsection{Study Area and Case Study}

Located in Kabul province, the city of Kabul, which encompasses an area of 1622 square kilometers, is the capital of the Islamic Republic of Afghanistan in the country's eastern section. It is home to about 4.4 million people, almost half of whom are women as of 2020 [102], and it has 22 urban districts, each of which is divided into 8 to 113 subdivisions called Gozars. Kabul city has 911 Gozars, the smallest urban subdivision units, which are 
institutionalized as subdivisions that have a representative called a wakil and have set or customary boundaries [101]. These century-old, social and physical units are also found in surrounding cities as well as other Islamic countries [103]. These traditional neighborhoods, which are organized around a religious building, include bazars, community gathering places, and other daily facilities. Around them, strong social ties and relations have been forged among residents enmeshed in the social order, security, and identity of their communities [104].

KM made a decision to make a strategic development plan for Gozars based on the ground truths of public insights by opening a deliberative communication line using our system to promote equal consultations and harness citizen-organized suggestions offered in response to the following questions: (1) What functions do you believe are successful in Gozars? (2) What is your opinion of these units? (3) Can their functions be strengthened? (4) What policy changes should be initiated regarding these units? Thus, an open-call idea was used to post invitations to all the residents of the municipal districts to participate in the planning process through online discussions and deliberations. We created a virtual room for all 22 districts of Kabul city, labelled as 1-22 (Figure 1) to collect answers to these questions by conducting this experimental participatory planning. $\mathrm{KM}$ is the responsible municipal government for Kabul city. In this study, KM, Kabul municipality and Kabul city are synonym.

In this experimental participatory planning, the following are the main statistics from all the districts in the system. A total of 733 citizens joined (females $=124$ and males $=609$ ) who made 874 posts, which generated 1893 elements: Issues $=599$; Ideas $=576$; Pros $=474$, and Cons $=244$. The average node extraction confidences of the element labels for these four labels are described in Section 3.5.5. We established the labeling of the generated elements by our system-node extraction and the relationship of their elements through our system-link extraction [105]. Unlike conventional town-planning processes or meetings, our experimental participatory e-planning approach involved many diverse individuals from Kabul districts.

Note that in our previous research in 2013, we conducted various surveys and studies on Gozars, including a questionnaire survey with only the Gozar representatives of four districts of Kabul city and a field survey [101,103]. We also surveyed the lifestyles and the daily activities of the residents [104]. Due to budget, time, and security issues, we were unable to cover people on a large scale with traditional techniques. Unfortunately, we also met much public apathy during our surveys.

\subsection{Planning with a Gozar's Citizens}

Currently, a Gozar's residents nearly always discuss their common problems at meetings held in masjids that exclude the participation of women and religious minorities. Next the wakil reports the meeting's conclusions to the KM [101,103]. However, this approach obviously restricts consultation and participation to just a few people, creating bias. Such biased representative reporting cannot be avoided because each wakil may be influenced during the facilitation process and when reporting insights to the KM. In addition, the scale of voices (needs and suggestions), their content labeling, and organizations using man-power are critical problems for policymaking institutions. Most critically, based on Kabul's current security situation, embracing the traditional forms of participation for collecting policymaking insights is dangerous and untenable because the government cannot ensure the safety of large-scale gatherings.

As a result, merging top-down and bottom-up processes needs collaboration through which local governments and communities work together through online interaction with technology support. KM understands that it has become increasingly necessary to use a complementary tool to support equal consultations, lead fair discussions that reflect neutral facilitations, and most importantly, label the voices generated by citizens based on a ground truth at scale. 

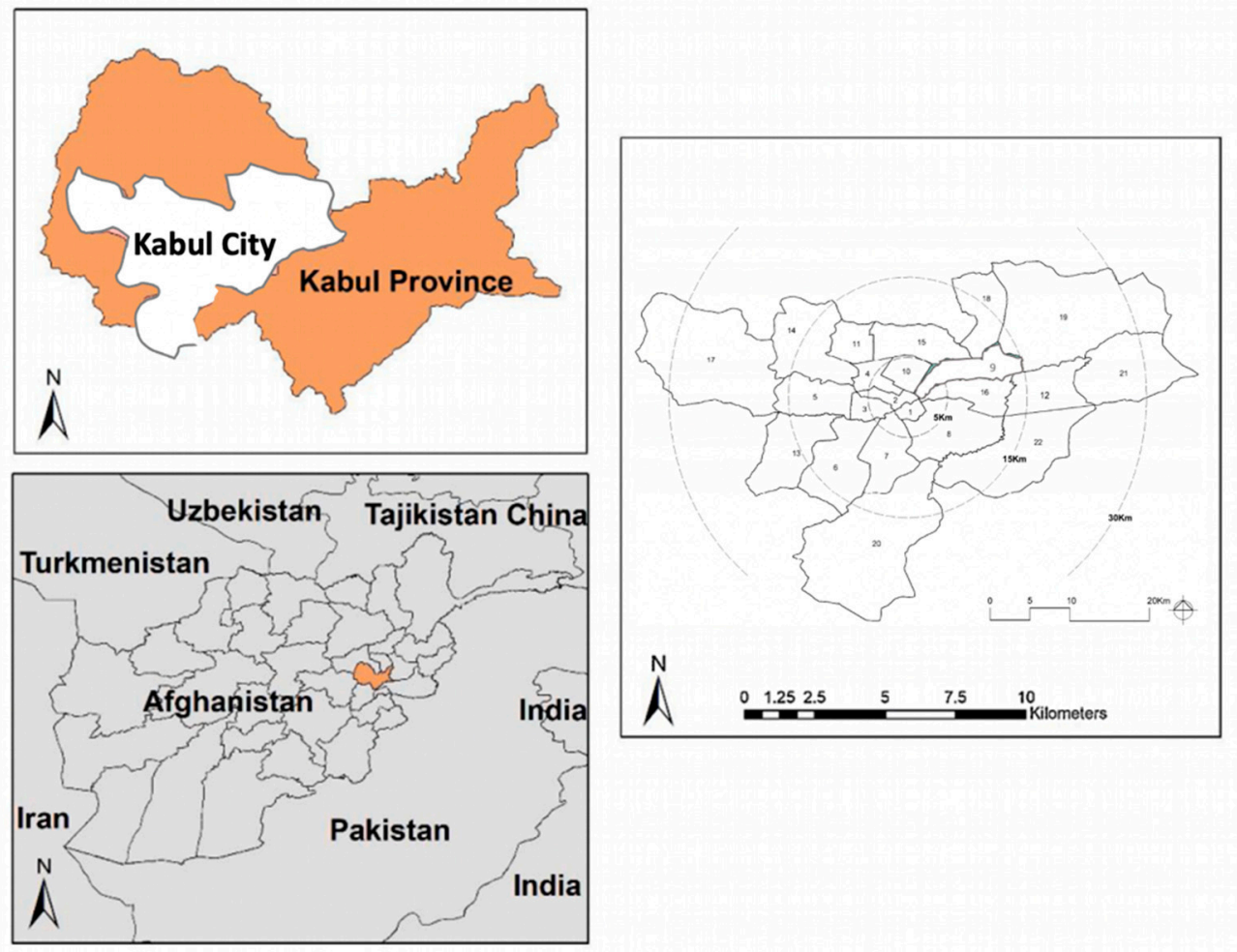

Figure 1. Location of study, 22 municipal districts of Kabul city, Kabul province, Afghanistan.

\subsection{Participation Motivation}

The type of motivation impacts civic engagement [106]. To support it, we have to consider both extrinsic and intrinsic motivation for participation. Personal interests and hobbies are examples of intrinsic motivation, and extrinsic motivation provides compensation for work [60]. Extrinsic motivation can be further divided into financial (e.g., monetary reward), social (e.g., a desire to learn and improve one's abilities, knowledge gain, and experience), and organizational (e.g., society ranking prospects) motivators [60]. We chose gamification [36] and ranking systems [35] of our system to reward points for posting, replying, and liking within a discussion thread. Because these points simplify the recognition of active discussions and potential ideas, they might improve one's abilities through knowledge gains [35]. An incentive mechanism used in our system is based on mutual benefit [54]. There are two types of points: active and evaluated. Participants earn 10 points for posting, 5 points for replying to a post, and 5 points for liking a post. They earn 15 points when another user replies to their posts and 5 points for likes. When a post is liked, the parent post is also rewarded. The propagation ratio is $50 \%$. For example, if a post is liked, it earns 5 points, its parent post earns 2.5 points, and its grandparent post earns 1.25 points.

Kabul city officials also considered a social and organizational acknowledgement process to motivate participants to join the discussions. Active discussants received appreciation messages from Kabul city officials.

\subsection{Participatory e-Planning Joint Research Initiative}

For the past two years in Afghanistan, we have been investigating alternative methods of participation to complement traditional methods and tools [42,43]. In early 2019, for the first time, on behalf of Nagoya Institute of Technology (NITech) we discussed such issues and our hypothesis with Kabul's mayor. We believed that his administration would welcome an online soft solution that advocated participatory planning and adopt such new methods as e-participation at scale because it lowers security constraints, time concerns, 
gender obstacles, and provides people with the opportunity to participate in democracy anywhere and anytime [39]. After conducting a series of online meetings, we finally reached an agreement over a memorandum of understanding $(\mathrm{MoU})$ of a joint research program called CCDP. Both NITech and KM agreed and signed using D-Agree as a complement participatory tool to promote real-world e-participation and engage in public discussions at scale.

Our main objective was empowering discussion between local governments and communities and climbing the participatory e-planning ladder in Afghanistan. We proposed the following research questions: "Are online-participatory-support systems likely to increase participation in Afghanistan?"; "How might crowdsourcing solve Kabul's complex urban issues?"; and "How can a complementary participative tool be adopted to propel e-communities forward?" Our hypotheses wondered whether KM's intention to collaborate through a platform would give citizens a greater level of engagement in the issues, harness solutions, and enable more active participation in municipal planning. Apart from those benefits, online participation allows for more organized and substantive participation from interested stakeholders and could lead to more social-collective awareness and intelligence in municipal planning. Because our system annotates submitted opinions into four elements based on deep learning links and node extraction, its elements with the highest confidence are labeled as discussion elements. To the best of our knowledge, our agreed-upon initiative is the first practical example of a collaboration between academia and a local government in Afghanistan for stimulating participatory e-planning.

\subsection{System Outline}

Our system, D-Agree [12], is a text-only discussion-processing and decision support system based on artificial facilitation. It is used to host ongoing city planning debates by gathering, facilitating, extracting, and visualizing real-time discussion summaries. Technically, our system provides a vehicle that facilitates crowd-scale deliberation to promote collective awareness and consensus building by harnessing collective intelligence for policies and decision making $[11,54]$.

Our system supports four basic elements of engagement [3]: (1) interest through city-citizen initiatives and an incentivized point system; (2) knowledge through real-time discussion visualization; (3) participation by anyway and by anyone; (4) moderated discussions and ceding the floor to others. Our methodology supports four basic principles of engagement: (1) inclusivity at scale; (2) transparency to reflect the best solution, suggestions, and needs as it is concerned [22]; (3) interactivity by equitably leading the reasoning process without facilitation bias; and (4) continuity that links the process to action [37].

Our system is composed of two modules: front-end and back-end architectures. The former is the system user interface (UI), which interacts with users through discussion websites or other social platform messaging services. The back-end hosts four agent modules: (1) a conversational agent; (2) a proactive agent; (3) an NLP engine; and (4) an argumentation engine. The top part of picture $a$ in Figure 2 shows the front-end, and the bottom part shows the back-end architectures of our system. The right part of picture $b$ in Figure 2 shows the adopted discussion structure, and the left part shows the discussion development in our system. 


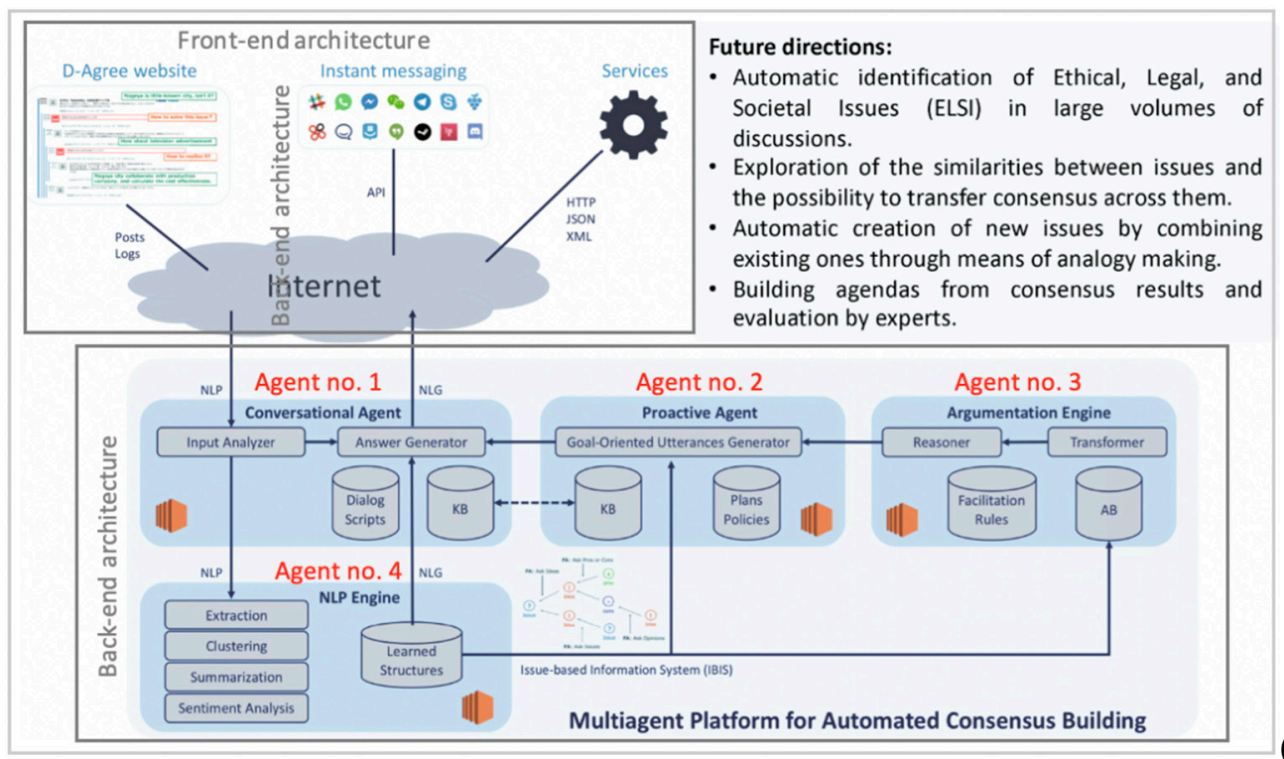

(a)

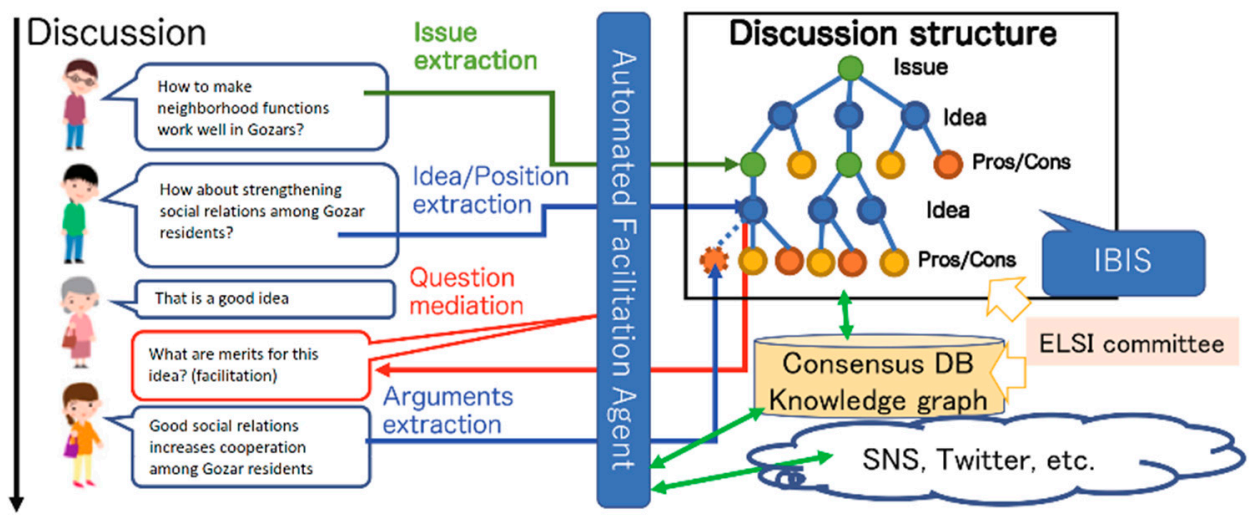

(b)

Figure 2. ((a), top) Outline of system front-end architecture, ((a), bottom) outline of system back-end hosting four types of agent modules, ((b), right) outline of discussion architecture and labelling, and ((b), left) outline of real discussion flow and human-to-human, agent-to-human and human-to-agent interactions.

\subsubsection{Conversational Agent}

Our system implements a conversational agent that is introduced to online discussions to interact with humans. Such agents mediate discussions by posting facilitated messages and replying to user posts based on the number of facilitation policies and also complement humans to encourage reaching a consensus for solving problems on online communities by mediating and supporting human-generated posts. Such so-called artificial or AI facilitators (AF) moderate online discussions to develop argumentation-reasoning processes and generate opinions in online-discussion platforms. They help discussions proceed more efficiently and productively by removing human-based facilitation turn-taking biases and time constraints. The agent adopts predefined facilitation messages based on some predefined policies with a specific semantic based on the post mining of users to decide whether to ask the author of the posted opinion to provide a support argument related to her posted opinion or to request other users to provide supportive arguments related to that posted opinion. The agent can summon other IBIS's elements, such as issues, ideas, or pros/cons. This process performed consistently well and improved the solicitation of opinions. More details on agent introduction and posting are described in Section 3.5.5. The bottom part of picture $a$ in Figure 2 shows the back-end architecture which includes a conversational agent, labelled as agent no. 1. 


\subsubsection{Proactive Agent}

We implemented a proactive agent to set the conversational agent's behavior based on three predefined plans: (1) a consensus policy; (2) a brainstorming policy; and (3) a voting policy. The consensus is amid an outcome-based discussion. This policy supervises a discussion flow based on a time plan and a discussion phase, including posting startup messages, moves for mediating a main discussion (divergence), proceeding to deliberation (convergence and evaluation), and ending with a conclusion. In each discussion phase, a proactive agent forces the conversational agent to proceed by the categories of the sentences generated by the agent as post messages to interact with the participants. The proactive agent can be equipped with an agenda to lead a discussion toward its desired outcomes. The second policy, brainstorming, is aimed for discussions that lack the above phases. The third policy is voting. It allows participants to vote for someone's contribution by liking a post.

In this study, due to its experimental nature, we set a consensus policy for the proactive agent and adopted a divergence discussion phase to collect a variety of opinions. The bottom part of picture $a$ in Figure 2 shows the back-end architecture which includes proactive agent, labelled as agent no. 2 .

\subsubsection{NLP Engine}

The bottom part of picture $a$ in Figure 2 shows the back-end architecture which includes NLP agent, labelled as agent no. 4. A natural language processing (NLP) engine employs and extracts the posts of users. For all of the data posted by each user, a set of features is automatically learned by a discussion-structure module using machine learning techniques. The engine performs content labeling, document summarization, and sentiment analysis. We extract the discussion's structure in real-time. These extractions include node and link extractions [105]. The former automatically classifies the sentences in the discussion into four classes: issues, ideas, pros, and cons. The link extraction predicts a relationship between sentences. These four classes are based on the Issue-Based Information System's (IBIS) structure proposed by Warner Kunz and Horst Rittle in the 1960s [107]. The discussions in our system are modules in the IBIS style, which represents the discussions by a combination of tree types of elements: Issues, Positions (Ideas), and Arguments (Pros and Cons). The discussion trees in our system are represented by a combination of four types of elements: issues, ideas, pros, and cons. The IBIS structure is shown in Figure 3, picture $b$. Issues denote the common questions that stakeholders (city and citizens) aim to solve. Subsequent issues generated after the other issues are generalizations or specializations about related issues. The discussion theme or the topic setting is a high level of an issue, which Kabul city sets to harvest the wisdom of citizens to find innovative solutions. Positions denote possible answers or Ideas generated in response to related Issues or problems. Arguments refer to the opinions generated in response to the related positions. Positive opinions are represented as Pros, which are the potential advantages of the related ideas. On the other hand, the negative opinions are Cons, which might be their shortcomings. Each of these elements is called a node, and a relationship between the elements is called a link. The automated facilitation agent uses the IBIS structure to manage the discussion. For example, it suitably facilitates the extracted nodes [105]. Our platform's discussion-summarization system uses the extracted node and link information [105] to generate real-time discussion trees [34]. This system reconstructs a discussion tree of the whole discussion according to the IBIS structure and displays it for users. The structured and real-time visualized trees help participants learn while looking at a discussion's flow. One tree with branches (nodes and links) is structured for each discussion theme. Figure 3 shows the distribution of the discussion elements as a discussion moves toward a conclusion, and presents a clear mechanism that defines how the elements generated in our discussion system adopted the IBIS module. The picture $a$ in Figure 3 shows IBIS base argumentation development process, and picture $b$ shows the 
discussion argumentation structure, adopted. The obtained themed discussion will look like discussion development process and structure shown in Figure 3.
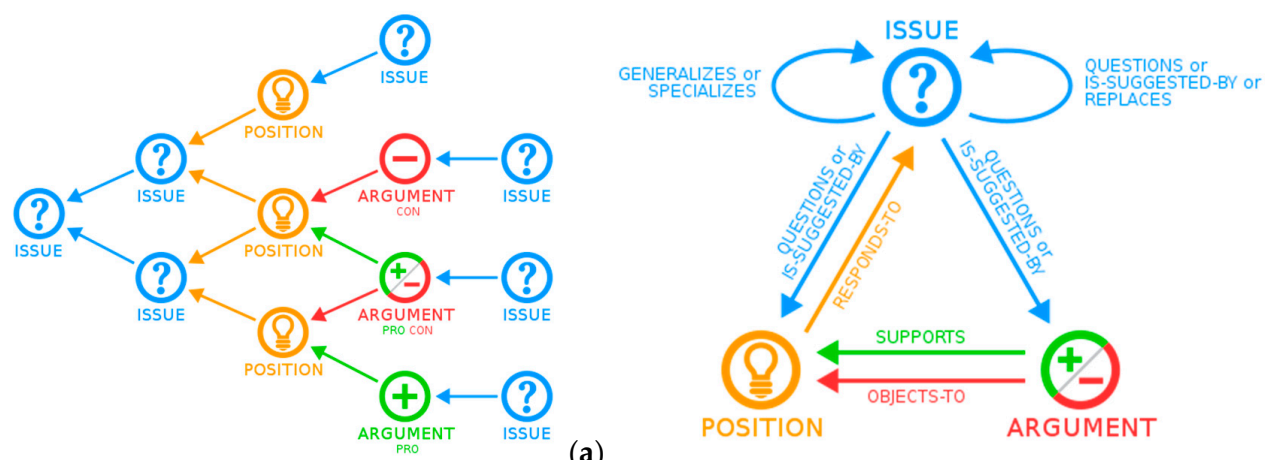

(a)

(b)

Figure 3. Outline: (a) IBIS-based reasoning process and (b) IBIS-based discussion argumentation structure flow adopted by our system.

\subsubsection{Node and Link Extraction Method and Training}

Node and link extractions are based on a deep learning method [105]. As training data, we used our original dataset of discussions conducted in English using our system. These discussions, which included 27 different topics, such as social issues, were held by foreigners living in Japan (translators, English teachers, and Nagoya Institute of Technology students). Each topic was discussed by four people. We used 2050 pieces of data for training the node extraction and 955 for training the link extraction. Annotation was done manually. We used BERT [108] and Dense for the node extraction model and fastText [109] and bidirectional long short-term memory (Bi-LSTM) [110] for the link extraction model. Bi-LSTM is a type of recurrent neural network (RNN) [110]. The evaluation results of the node extraction using three-fold cross-validation are shown in Figure 4, as are the evaluation results of the link extraction using leave-one-out cross-validation [111]. We found the following link extraction results: idea $\rightarrow$ issue; pros $\rightarrow$ idea and cons $\rightarrow$ idea: $0.488 ; 0.235$ and 0.209 . We did not evaluate issue $\rightarrow$ idea and issue $\rightarrow$ pros/cons due to insufficient annotated data. We proposed a new method to improve the accuracy of the node extraction [112]. With a Graph Attention Network (GAT), we can train not only sentences but also graph structures [113]. A method using GAT has shown good results [112], and we are working on its implementation in our system.

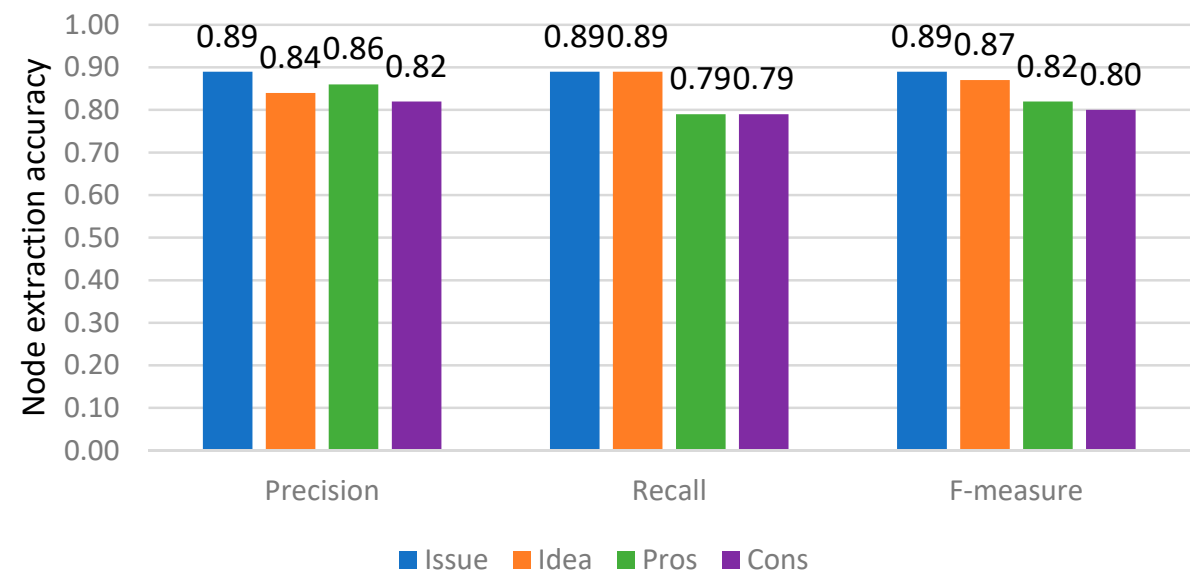

Figure 4. Average precision, recall, and f-measure results of node extraction.

3.5.5. Node Labeling and Selection

A node is an element extracted from a user's generated and posted opinions. An opinion may contain a range of elements $(1-n)$ depending on the quality and the stance of 
the generated opinions. In practice, in node extraction, we represent it in terms of natural language sequences composed of words. The input is the embedding of each word using fastText [109], and the output is a normalized probability. We consider a sentence and label it within a generated opinion as one node type out of four expected labeling types that require the highest probability among the three other labels. For example, to explain the real-time labeling further, we consider the discussion interaction among humans and AI shown in Figure 2(b, left). A participant asks, "How can we make neighborhood functions work well in Gozars?", AI label it as Issue using node extraction [105], Another participant sees the message as issue and posts an answer (Idea): "How about strengthening the social relations among the Gozar residents?", the AI label it as Idea. Then a third participant joins their conversation and shows agreement (positive opinion) with the second participant opinion by posting: "That's a good idea.", AI label it as Pros (positive opinion in response to posted idea). Now, based on the sentiment analysis of the previously posted opinions and predefined threshold of three people, the conversational agent introduces an idea into the discussion to advance it by collecting the arguments of the others on the proposed ideas by posting a facilitation message: "What are the merits of this idea?" Finally, the fourth participant sees the AI facilitator's post and posts a positive response to the proposed idea of second participant: "Good social relations increase cooperation among Gozar residents." AI label the fourth discussant post as Pros (positive opinion in response to posted idea). This was one of actual example of discussion flow in our study.

Real-time node extraction was performed in our system, and all types of submitted opinions were extracted as nodes with labels in a tree structure [34] to establish relationships among them through link extractions [105]. For example, for the first participant, his posts are embedded using a fastText [109], and the output is a set of generalized probabilities: \{cons: 0.00633775 , ideas: 0.00077646505 , issues: 0.99271494 , pros: 0.00017085881 \}. Then the system normalized the set by acquiring and labeling it as an Issue as the highest probability (0.99271494) of the submitted opinion. The average precision, recall, and $\mathrm{f}$-measure of the node extraction (labeling) results with respect to the ground truths in our study are shown in Figure 4.

\subsection{Argumentation Engine}

Finally, the fourth module is an argumentation engine that reasons and infers from the structured arguments. Classification is based on the characteristics of the IBIS structure. Output is visualized to predict the posted item's traits and behaviors as issues, ideas, and various pros and cons. In practice, the argumentation engine needs to decide whether an argument's subsets are valid based on predefined semantics. The bottom part of picture $a$ in Figure 2 shows the back-end architecture which includes argumentation engine, labelled as agent no. 3 .

\section{Experimental Participatory Setting}

\subsection{Topic Setting}

Two objectives shaped our selection of a discussion theme as a high level for Kabul city urban issues. First, the KM theme is related to the issue whether the function of Gozars work well or unsatisfactorily for promoting public engagement by collecting insights related to Gozars for policy-making. Second, we wanted to verify the effect of our systemnode extraction in discussion themes by setting different stances for the same themes. Based on our decisions while considering the suggestions from the KM theme, we set three discussion themes to collect public insights and analyzed the discourse structure and sentiment of three themed discussions. Although the discussion themes were closely related, their stances are different. The citizens discussed the following three themes using an open-call method:

Theme 1: What are the satisfactory functions for the Gozars?

Theme 2: Which functions from the list of 18 are satisfactory/unsatisfactory and why?

Theme 3: What are the expected solutions to improve the Gozar functions? 
Theme 1 was discussed for three days (May 12 to 14), and seven days were allocated for theme 2 (May 15 to 21) and theme 3 (May 22 to 28). The first theme collected the level of citizen satisfaction regarding Gozar functions and indirectly performed participationsentiment analysis to identify the satisfaction from the public participation in the themed discussion. While looking at the theme stance, our proposition for Theme 1 argued that as more people participated and discussed, the more satisfactory the Gozar functions might be. The structure of Theme 1 was satisfactory-giving.

Theme 2 collected the level of the satisfactory or unsatisfactory functions by addressing specific functions from a list of 18 functions and asking the participants how to build an issue-giving consensus at the collective level. Our proposition for Theme 2 was a more specific one that addressed a question and asked about the reasons of failure. We thought that more people might be motivated to participate and discuss. The structure of Theme 2 was closed-ended and issue-giving + why. We collected 18 functions from our previous research studies in 2013 [103,104] and these functions were divided into four sections: (1) governance, (2) social, (3) physical, and (4) safety. These functions and their performance percentages are described in Section 5.2.

Theme 3 collected the expected solutions to improve the unsatisfactory functions at the collective level. The structure of Theme 3 was open-ended issue-solving. We assumed that the flow of themes would explore a managed process, such as defining what works, what fails and why, and finally, to find solutions to the failures at the collective level. Furthermore, the discourse-centric collective intelligence of each theme helps us perform sentiment analysis and social behaviors related to functions from obtained discussion structures. The three themed discussion experiment was carried out online for 18 days from 12 to 28 May 2020.

\subsection{Open-Call Setting}

The city wanted to engage not only urban experts but also the public to identify Gozar issues and gather their policymaking suggestions, and thus we decided to use D-Agree. The process started by posting an open call [54] for participation on the Kabul municipality's home page (HP) and Facebook page. This was the first time that Kabul's municipal government had asked its residents to join large-scale discussions using open call idea and online decision support system. All the opinions of the citizens were collected by D-Agree using the following Kabul city official HP link: https://km.gov.af/3657/ (accessed date 12 May 2020). The KM joint task team was comprised of representatives from the office of the mayor, the planning and policy directorate, the publishing and media directorate, and the directorate of citizen coordination and social affairs, Kabul city. This team invited Gozar citizens to participate in our social experiments. We posted daily invitations to participate for 18 days. We created a virtual discussion room for each of the 22 urban districts of Kabul city. Based on their residences, Gozar citizens could join their virtual discussion rooms using discussion codes. The participants discussed Themes 1, 2, and 3. A total of 733 people joined, 124 of whom were female, including Anarkali Honaryar, the first Afghan Sikh and non-Muslim member of Afghanistan's national assembly. In addition, seven registrants joined from other religious minorities, including Sikhs and Hindus.

\subsection{Experiment and Agent Setting}

The server management side of our system was deployed on Amazon's elastic compute cloud (EC2) infrastructure, and each module was allocated to a separate EC2 instance. The following is a link to our system: https:/ / d-agree.com/site/en/ (accessed date 12 May 2020). Its user interface (UI) is shown in Figure 5, as well as, the top part of picture $a$ in Figure 2 shows the front-end architecture which includes D-Agree's website (UI). 


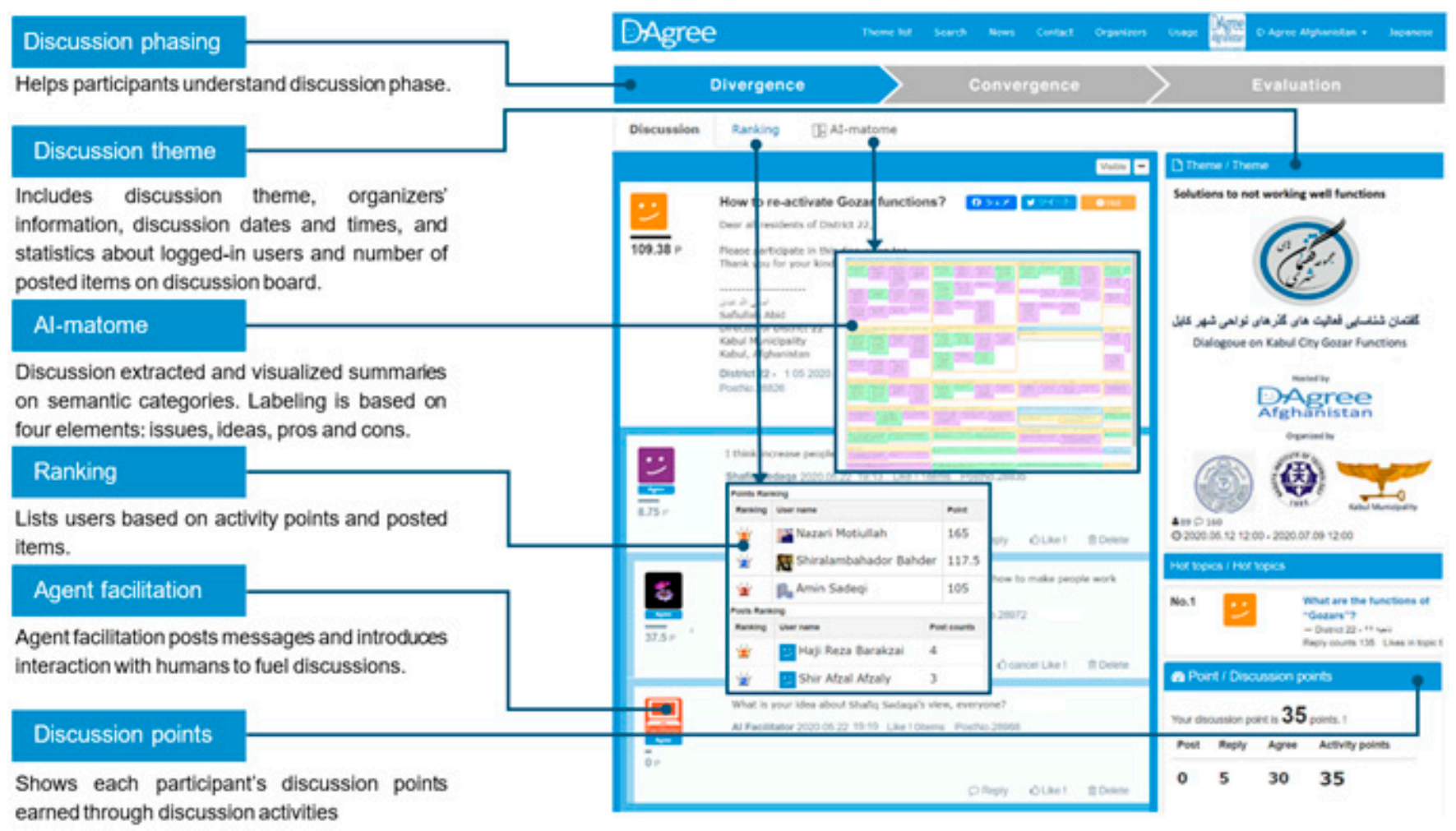

Figure 5. Snapshot of user interface in D-Agree during Kabul city district 22 social experiment.

The following are the main components of the interface: (1) discussion phases (divergence, convergence, evaluation, and conclusion), which include discussion thread areas and participant discussion scorecards, where participants post messages and interactions with others and the AI facilitator; (2) a ranking system, which is a gamification incentive mechanism that shows the ranks of all participants; (3) an AI-based discussion summarization (AI-mathome) through which participants can see the whole discussion as a tree as well as relationships among nodes. In Japanese language, mathome means summary.

The interaction between the participants and the agent was controlled with two parameters: a $1 \mathrm{~min}$ period specific to Amazon CloudWatch [114], and a threshold of three people. This threshold sets the number of human messages that the AI facilitator (agent) must count before joining the discussion. For instance, in the excerpt of the discussion in Figure 2 (picture $b$, left), the AI facilitator waited until three messages had been posted by human participants before posting her (AI) facilitated message. In this study, we revealed the agent identity as AI facilitator. Besides the artificial facilitator, we used two types of human facilitators: (1) those from district offices who sent supportive messages to assure the people that their opinions are being heard and will be considered: "Thank you for raising this issue. We will address it." (2) We also invited independent urban experts to ask specific questions about Gozar matters to facilitate discussions and obtain more details. The comparison of participants replies in $\mathrm{AI}$ and human posted facilitated messages are described in Section 5.4.

\subsection{Discussion Data Collection Setting}

The discussion contents were set as annotated discussion data from our system (Table 1). Based on KM suggestions, we set the annotation discussion data for the system. KM wanted to collect actual, extracted insights to learn needs and suggestions based on the ground truths of each district. After the discussions, we generated post-discussion annotation files that included all the items mentioned in Table 1. We assumed that the extracted insights elements, and their evaluated and received points of the elements, may guide policymakers when they are making Gozar policy. 
Table 1. Collected and annotated data from 22 municipal experimental participation.

\begin{tabular}{cl}
\hline Items & \multicolumn{1}{c}{ Description } \\
\hline Entry ID & Integer that identifies parent post \\
\hline Title & Title of post \\
\hline Body & Original posted opinion \\
\hline Thread ID & Integer that identifies post as a thread \\
\hline Parent ID & Integer that identifies a post and links it to a parent \\
\hline Name & Author of post \\
\hline User group & Integer that identifies a group \\
\hline Labeling confidence & Node extraction result \\
\hline Entry ID & Integer that links a child post to a parent post \\
\hline Post time & Time of opinion's submission \\
\hline Text & Extracted node contents \\
\hline Node ID & Integer that identifies a node \\
\hline Type & Type of label \\
\hline Type confidence & Set of node extraction results \\
\hline Point & Evaluated points from user activities
\end{tabular}

\section{Results}

The results of the quantified data of the three discourse themes are shown in Table 2; the results of the general experimental participation are shown in Figures 6-10; the results of the qualitative data are shown in Figure 11; the results of the performance percentage of the neighborhood functions are shown in Figure 12; and the results of the formal and informal settlements locations comparisons are shown in Figure 13.

In the 18-day period, 733 Gozar residents created accounts and participated in one of the 22 experimental participatory-planning sessions (Figure 6). We obtained 874 opinions from the registered participants (Figure 8), which were submitted as initial posts and subsequently classified by AI into 1893 (Figure 7) discussion components to identify their real discourse insights. Based on the initial submitted opinions, the final discussion structure included 599 issues, 576 ideas, 474 pros, and 244 cons (Figure 8).

In our first finding, we found no correlation between the number of participants in the 22 municipal online discussions and a district's population or the number of dwellings in it (Figure 6). We assumed that districts with more informal areas are more likely to have unsatisfactory Gozar functions, and therefore, the residents in such areas will be more interested in discussing and sharing their needs and suggestions. Our assumption was based on that the informal areas have more issues than formal areas [101], thus, people in those areas willing to spent more times in formalizing their neighborhoods [115]. Even though we collected more participants and posts from informal settlements areas (Figure 12), we found no statistically significant difference in the number of registrants and posts between the two types of settlements. However, there was a statistically significant difference in the number of female participations between the formal and informal settlement areas. We received more female registrants and posts from informal settlement areas $(n=108,87 \%)$ than the formal areas $(n=16,13 \%)$. This is because the women and girls are particularly vulnerable in informal settlement areas [103]. This can be related to the findings by Mathew French [115] that communities with lower socioeconomic levels, such as Afghanistan, are more willing to invest personally in formalizing their neighborhoods. Figure 8 shows the number of participants and posts, and Figure 9 shows the IBIS elements for 22 municipal districts of Kabul city. 
Table 2. Summary of social experiment's quantified data of districts 1-22.

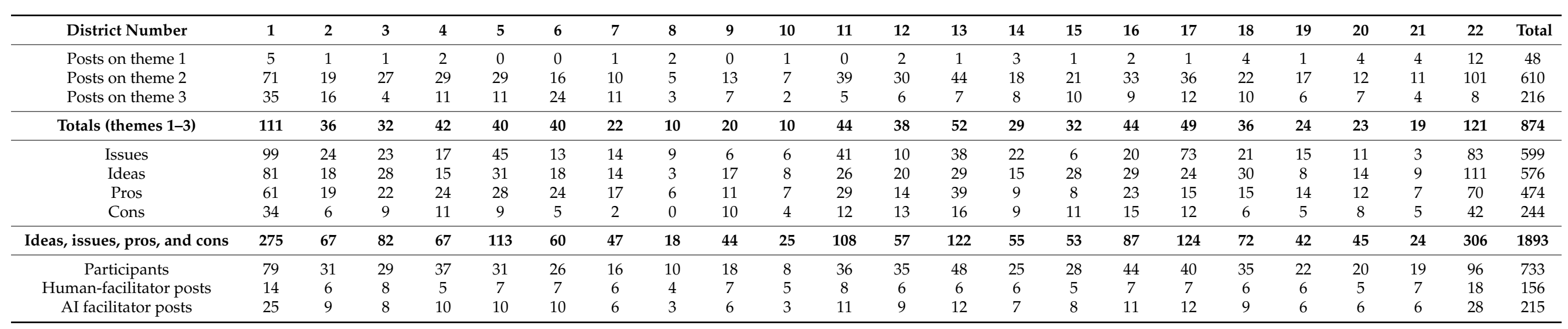




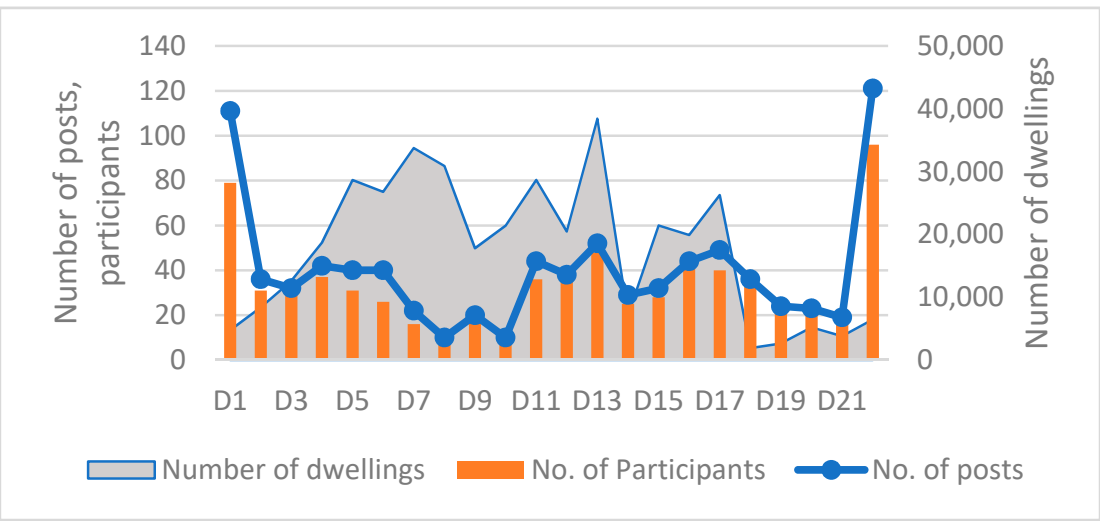

Figure 6. Number of participants and posts from districts and dwellings (D1 D22)

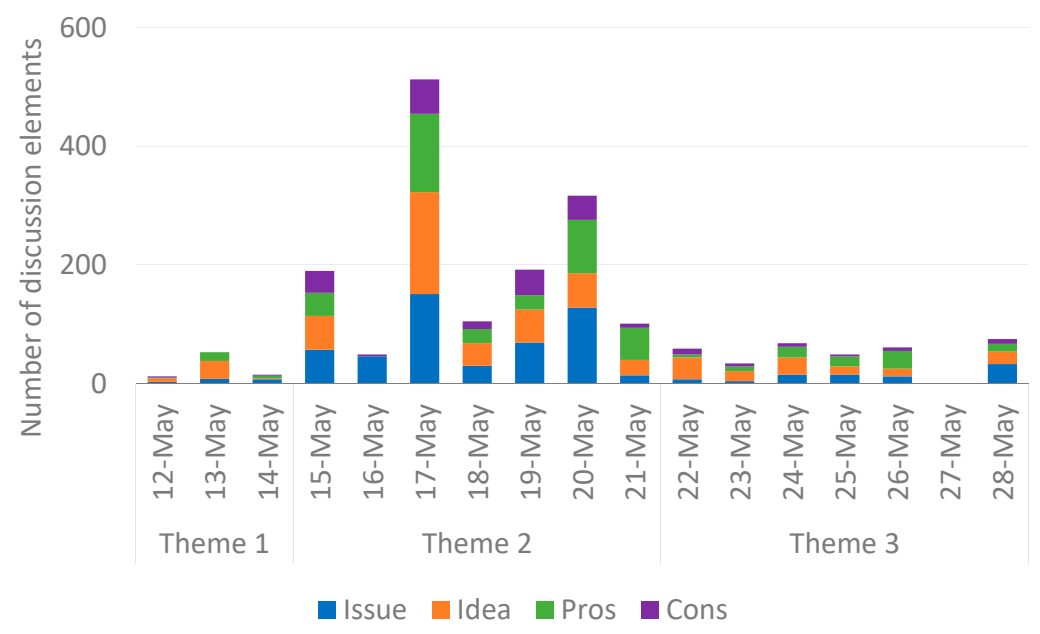

Figure 7. Daily distribution of four themed IBIS elements: blue (Issues), orange (Ideas), green (Pros), and purple (Cons).

From the results of content analysis of themed discussions, our second finding suggests that the citizens were not satisfied with the performance of the Gozar working functions. Because they felt that most of the functions are being done unsatisfactorily, they are not interested in participating or discussing in Theme 1 . Hence, only people 40 attended, and they only made 47 posts in Theme 1. Figures 8 and 9 show the comparisons of participants submitted post and extracted IBIS elements in three themed discussions.

In addition, our finding suggests that Theme 2 (Figure 8 ) was greatly successful in engaging people in discussions both in terms of citizen participation (543) and discussions (611). We assessed and evaluated the contents of the three themes to find evidence of the successful and significance levels. Participants spent more time posting quality opinions and generated more elements from a post (elements per post $=2.4$ ) in Theme 2 than in Theme 1 (elements per post $=1.7$ ) or in Theme 3 (elements per post $=1.6$ ). The average daily opinions posted in Theme 2 were 87.3, exceeding the average daily opinions for Themes 1 (average posts per day $=15.7$ ) and 3 (average posts per day $=30.9$ ). The total number of participants and posts was also higher in Theme 2. Thus, participants were clearly motivated to spend more time participating in and discussing Theme 2 than for the other two themes. This is mainly because of the quality opinion submissions and theme stance: closed-ended questions from the 18 functions. The setting and the structure of the three themes were mentioned in Section 4.1. 


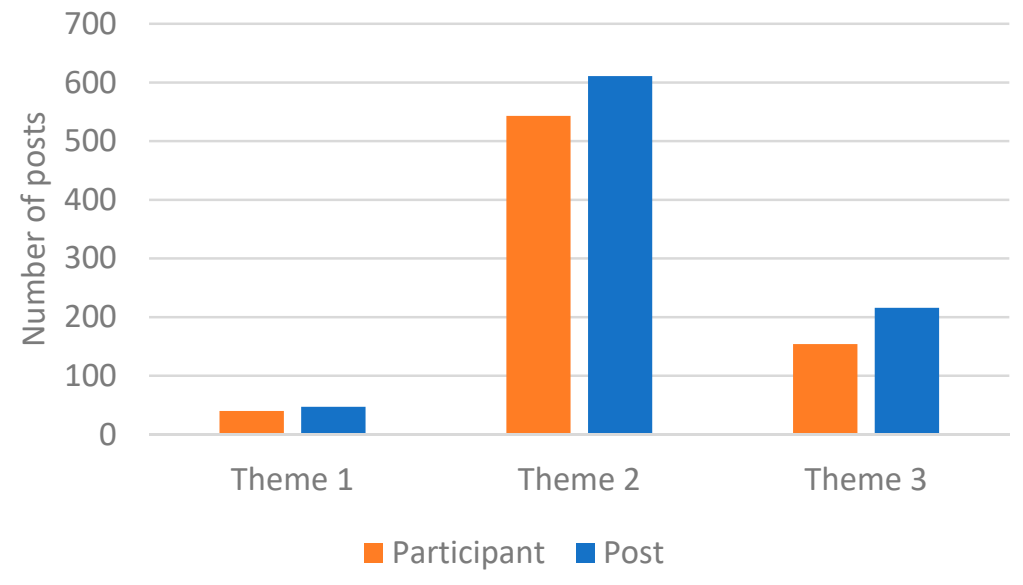

Figure 8. Distribution of participants and posts for three discussion themes

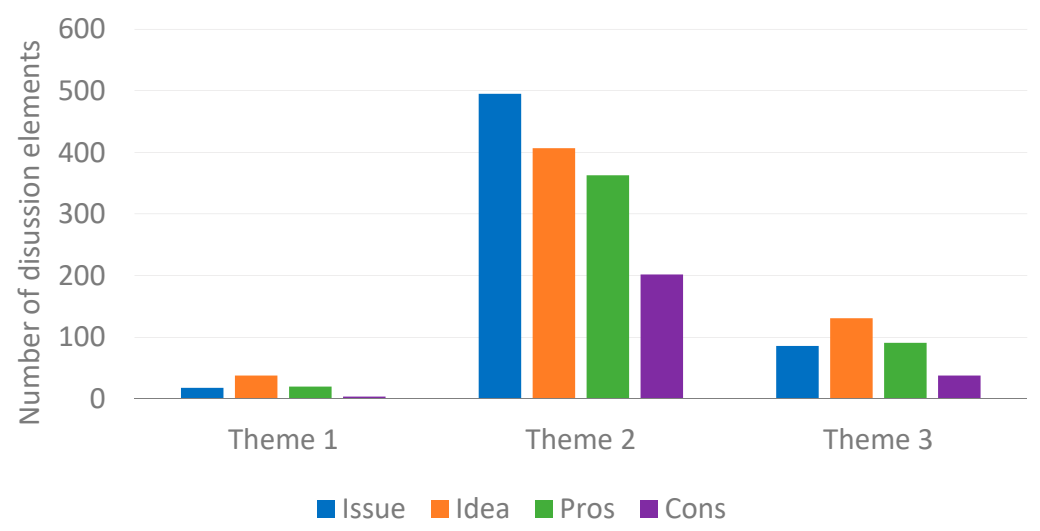

Figure 9. Distribution of IBIS elements for three discussion themes

Our third finding is that the total number of Ideas $(n=576,30.4 \%)$ and Pros $(n=474$, $25 \%)$ exceeded the total number of Issues $(n=599,31.6 \%)$ and Cons $(n=244,12.8 \%)$ for all three themes (Figure 9). This is because the conversational agent facilitated a message effect that raised solutions and suggested positive opinions in response to proposed solutions. However, if we look at each IBIS element, the Ideas $(n=169)$ only exceed the Issues $(n=104)$ in Themes 1 and 3 . The number of Issues $(n=495)$ was higher than the Ideas $(n=407)$ in Theme 2 because of the theme structure and the stance. For Theme 2, the participants generally discussed the poor performance of the functions rather than the satisfactory functions. When they discussed the unsatisfactory functions, the number of Issues increased during the discussions. However, the agent's facilitated messages (consensus policy) generated Ideas and Pros by soliciting solutions and positive opinions from the participants. Thus, our system provides extrinsic motivation, like gamification [36], a ranking system, which is an incentive mechanism based on quality opinions [35], and an artificial facilitator that stimulates discussion toward an issue-solving stance.

In Theme 2, the average daily number of opinions was 87.3 , which exceeds the average daily number of opinions for Themes $1(n=15.7)$ and $3(n=30.9)$. However, the average responsiveness rate was slightly higher in Theme 3 (posts per user $=1.4$ ) than for the other two themes (posts per user 1.1). In Theme 2, the average IBIS elements from posts (IBISs per post $=2.4$ ) exceeded Theme 1 (1.7) and Theme 2 (1.6). Figure 10 shows the average general response rate of participants in three themed discussions. In this study, IBIS elements, discussion elements, AI-led extracted nodes and discussion components are synonym. 


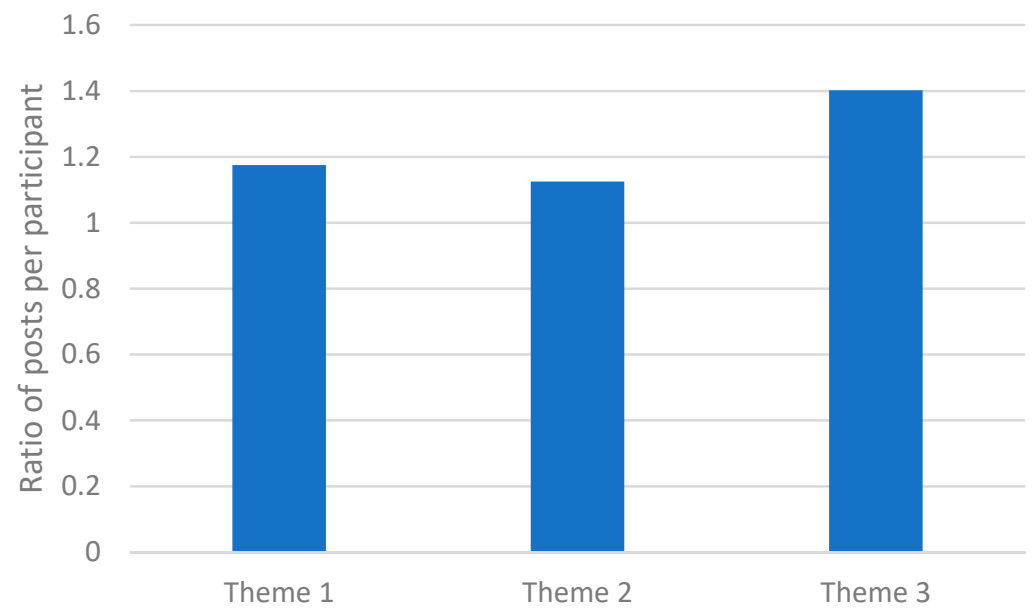

Figure 10. Distribution of average post per participant for three discussion themes.

Finally, our results show that our system is an efficient complementary participative platform that stimulates deliberative democracy and might also be an efficient crowdsourcing platform for innovative urban solutions in Afghanistan. Thus, other municipalities, such as Kandahar and Herat cities and the ministry of urban planning and land, expressed interest in our system by letters of intent.

\subsection{Qualitative Analysis of Annotated Themed Discussion Data}

The distribution of the discussion IBIS elements in each theme and the human-led qualitative content review of the AI-led annotations are shown in Figure 11. We used annotation data files of themed discussion, generated for each district virtual discussion space by our system, to analyze the frequency of IBIS elements by using Stata/SE 16.1 [116]. We used WordStat 8 [117] as a complement tool for content analysis of AI-led annotated discussion data. The AI-led labeling and annotation were mentioned in Section 3.5.5.

Considering the issues in all three themes, the most discussed topics (shown as controversial statements and questions) are the Gozar functions themselves: how to formalize or develop their functions, why do the functions not work, why are there no policies on Gozar functions, and how to revitalize their functions. The role and responsibilities of the wakils was the second most discussed topic. The opinions touched on the transformation of the wakil roles from the past to the present, bribery/corruption by current wakils, lack of policies and transparency about their roles/responsibilities, and problems in wakil elections. $N$ stands for number of submitted and extracted opinions that were annotated as IBIS elements in each theme. 'Other topics' (Figure 11), which refers to submitted opinions within each annotated element (Figure 10), were written in languages other than English or were not specifically pertinent to Gozar matters. This is because our system NLP and document summarization system can only understand English and Japanese as a natural language.

Ideas are the solutions to the statements or questions broached in the issues. Formalize, develop, or reform Gozar functions were the most discussed ideas. Reform the wakil roles and their responsibilities and eradicate corruption are the second most discussed topics among the ideas. If we compare the ideas in Theme 3 with the other two themes, in Theme 3 , which specifically asked for solutions, the people discussed more specific solutions. The most discussed solutions addressed improving the collaboration among the government, the people, and the wakils.

Pros, which are the merits of the ideas or positive responses by participants in response to proposed solutions (Ideas), included statements on how these ideas might improve the functions and increase people's participation, collaboration, mutual aid, and trust as well as how to encourage wakils to fulfill their responsibilities. Many statements 
appreciated the current discussion format and commented how such discussions might lead to improvement in the performance of the wakils' functions.

Cons or demerits to Ideas or negative responses by participants in response to proposed solutions (Ideas), included statements about the current role and the responsibilities of the wakils, the lack of citizen collaboration, the functions that aren't being done satisfactorily, and corruption. In summary, the people's views show that the reasons for the poor performance of many Gozar functions are that they are not formalized and that the wakil responsibilities are not being adequately met. If these issues are solved, collaboration will improve with the people and trust will grow among the people, the wakils, and the government. Figure 11 shows the qualitative content analysis on IBIS extracted insights in three themed discussions.

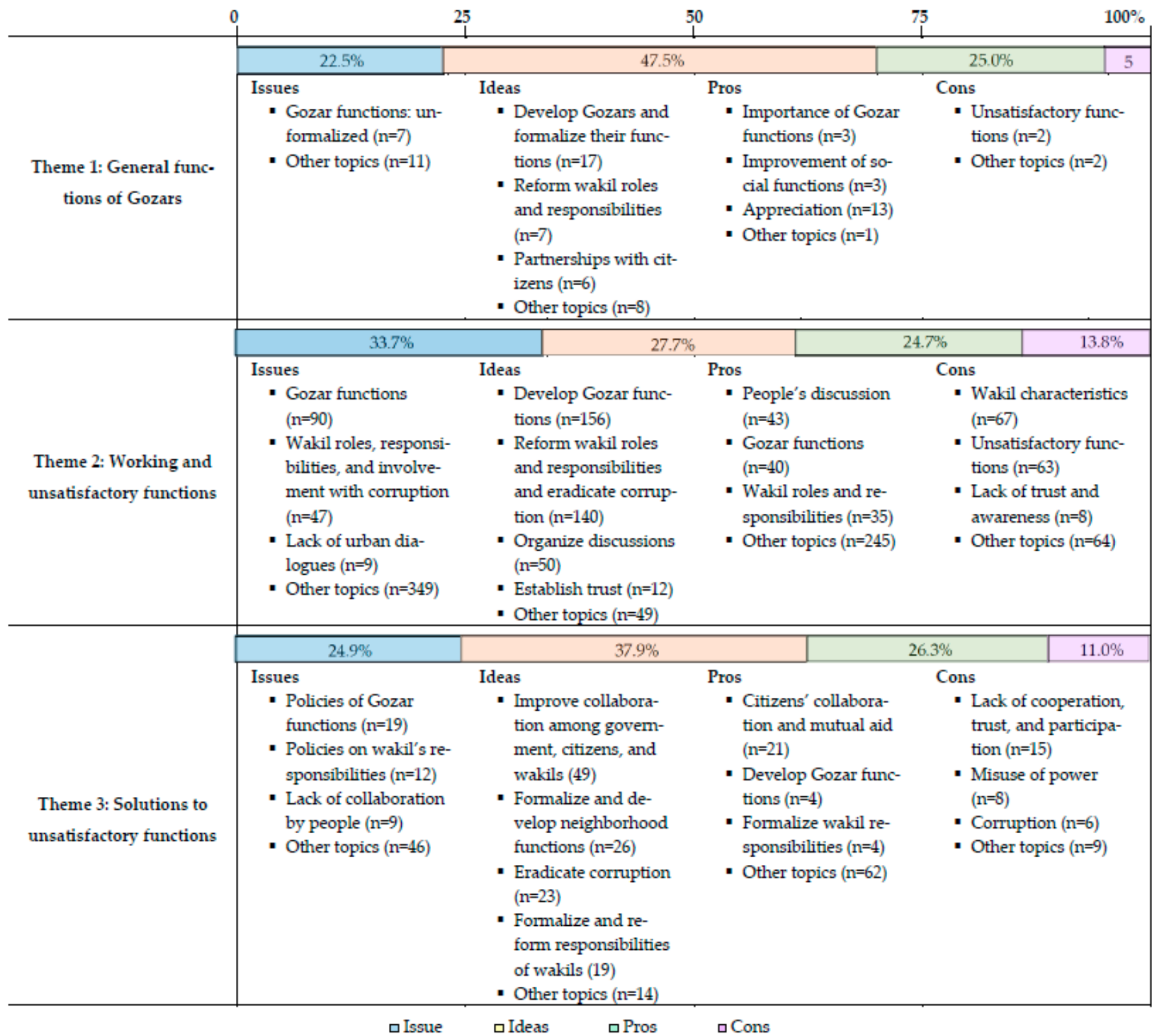

Figure 11. Most discussed topics based on AI-led extracted discourse summary of each theme's IBIS annotated discussion data: blue (Issues), orange (Ideas), green (Pros), and purple (Cons). 


\subsection{Comparision of Resident Opinions with Wakil Opinions}

Figure 12 compares the performance percentages of the residents and their opinions of the wakils. In addition, 18 Gozar functions (1 18) were divided into four sections: (1) governance (three functions, from 1 3), (2) social (six functions, from 4 9), (3) physical (five functions, from 10 14), and (4) safety (four functions, from 15 18) are listed in Figure 12.

In Theme 2, we listed 18 Gozar functions based on our previous research [101] and asked the participants to describe both the satisfactory and unsatisfactory functions in the Gozars. We gathered 610 opinions, the most among the themed discussion, and $261(42.8 \%)$ opinions discussed Gozar functions. A total of 115 participants described the functions as unsatisfactory or as being performed poorly; 56 thought that some/sometimes the functions were successful without providing details or specifying particular functions. A total of 90 participants specifically referred to the satisfactory functions from the list of functions we provided. We compared such specific responses of satisfactory functions with the responses made by the wakils from the same list of 18 functions collected by our questionnaire survey [101]. Except for dispute resolution (function no. 5) and community-market events (function no. 8), the wakils seemed to view the Gozar functions with more satisfaction. Perhaps this difference reflects the differences between the assumed role of the wakils and how they are related to the functions from the viewpoint of both the wakils and the citizens. Rating the performance of the functions is little more than veiled self-evaluations of the wakils' own performances. Other opinions included views about the wakils, civic engagement, social relations, building trust, and the formalization of the Gozar functions.

Perhaps the difference among the residence and wakil responses affected the policy decision makers at municipal level. As result, KM made a decision to select each wakil through organizing wakil election and call each Gozar resident to vote for their candidate in the future. Previously, KM directly appointed wakils without public consultation.

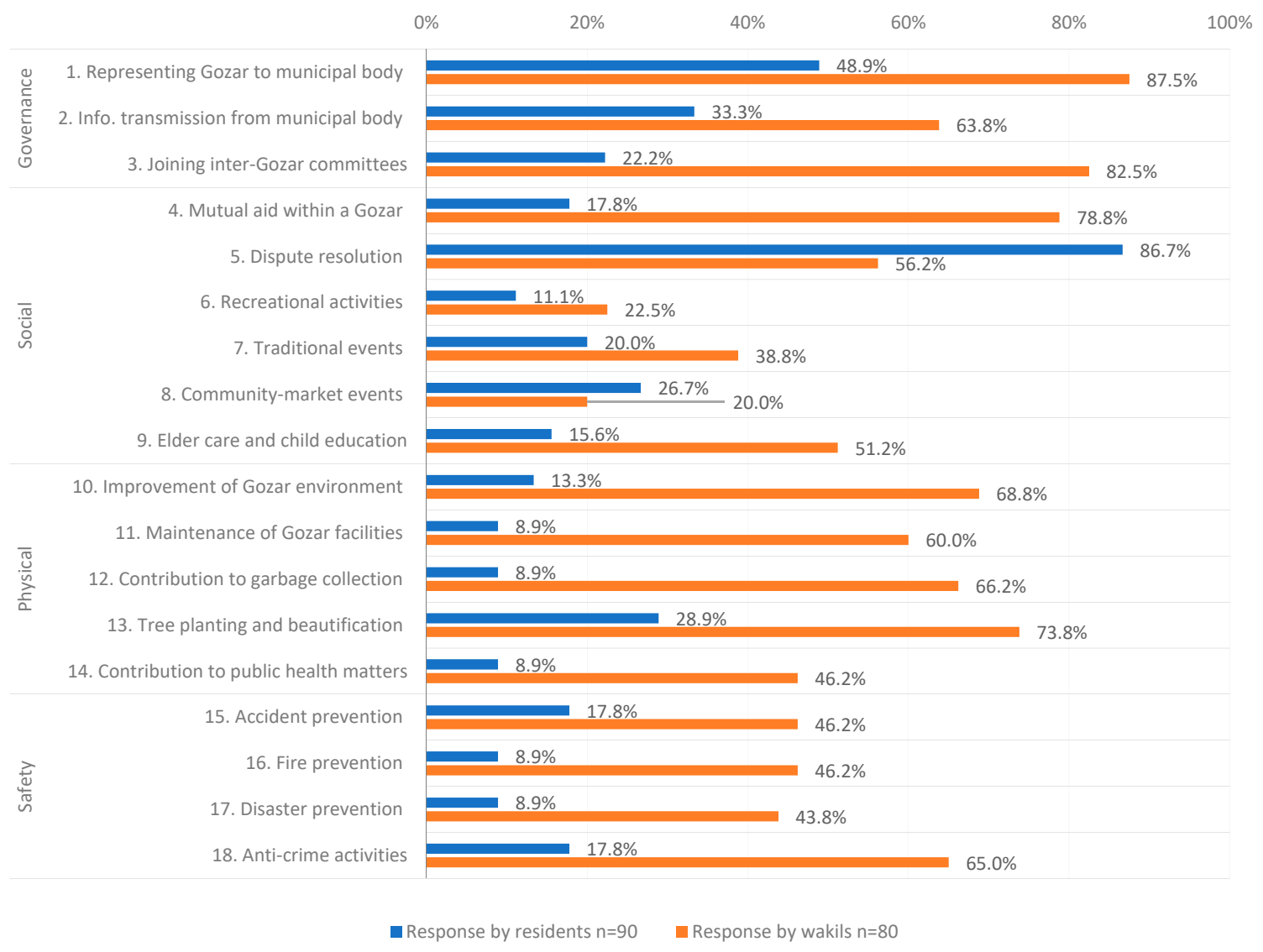

Figure 12. Comparison of performance percentage of neighborhood functions in Gozars between viewpoints of residents and wakils. 


\subsection{Comparision of Participation of Formal and Informal Areas}

Kabul city's population is increasing due to migration from rural areas [101]. Due to this exponential population development, Afghans had no choice but to construct informal settlements [118]. This unexpected development has led to it being one of the fastest urbanized cities in southern Asia, where more than half of the city's residential dwellings are informal [119]. Informal settlements are illegal settlements found all over the districts in the Kabul municipality. They have developed in different conditions during different periods of time [120]. Although, these informal settlements were home to $76 \%$ of the city's population in 2008 [121]; thus, KM had little choice but to adopt a regeneration approach [120] to develop these areas into formal areas through consultation with their residents.

Keeping this background in mind, the citizens' social and environmental needs are more focused on the formal areas, even though the informal areas face more issues than the formal areas [101]. Thus, KM collected social insights for a plan to satisfy the requirements of both areas based on the basic needs and suggestions. Thus, we investigated the breakdown within specific districts between the formal and informal settlement areas. Over half of the residential dwellings of the following 17 districts are informal settlement areas: D1 D3, D5 D10, D13 D16, D18 D20, and D22. Around 78.6\% of the total areas of these districts are categorized as informal settlements. Only five districts have more than half of their populations living in formal settlements areas: D4, D11-D12, D17, and D21. Around $73.9 \%$ of the total areas of these districts are categorized as formal settlements. In addition, districts with more than half of these informal settlement areas are home to a significant number of Gozars ( $n=722,79.25 \%)$. There are only 189 Gozars, and more than half of their residential dwellings are formal. Note that we assumed the districts as formal and informal based on the majority rule (districts with most formal and informal settlements).

Figure 13 compares the performances of the resident's participation and posting in the participatory planning of the formal and informal settlements areas. The districts (Figure 1) are labeled D1 22 (Figure 13). Most of the registrants $(n=566,77.2 \%)$ came from districts where more than half of their dwellings are informal (number of districts $=17,78.6 \%$ ). Most female participants $(n=108,87 \%$ ) were also from these areas. A total of 167 registrants came from the formal settlement areas, and only 16 were female. In addition, almost $78 \%$ (posts $(n=682)$ ) of the total submitted opinions on the themed discussions came from dwellings in the informal settlement areas. We gathered 192 opinions (around 22\%) from registrants in the formal settlement areas (Figure 13). This finding aligns with Sahab's study [101], which reported that informal areas have more issues than formal areas. The residents wanted to participate, discuss, and share their needs and suggestion with Kabul city. We collected 192 posts from 167 registrants of five districts, where more than half of the dwellings are formal, and 682 posts from 566 registrants from 17 districts, where more than half of the dwellings are informal settlement areas (Figure 13). Our finding suggests that informal areas settlements discussed more Ideas than formal area settlements. A total of 482 Ideas came from the informal areas, in which almost a registered resident from informal areas settlements posted an idea (participants $=566$; number of ideas $=482$; ratio $=0.86$ ) compared to that of formal areas (participants $=167$; number of ideas $=94$; ratio $=0.5$ ). As a result, an average 28.3 Ideas per district came from each district with most informal settlement areas to that 18.8 Ideas of formal areas. This finding aligns with Mathew French's [115] study stating that communities with lower socioeconomic levels like Afghanistan are more willing to provide more positive opinions in formalizing their neighborhoods. The statistics of the total numbers of posts, participants, and the labels of their discussion elements are shown in Table 2. 


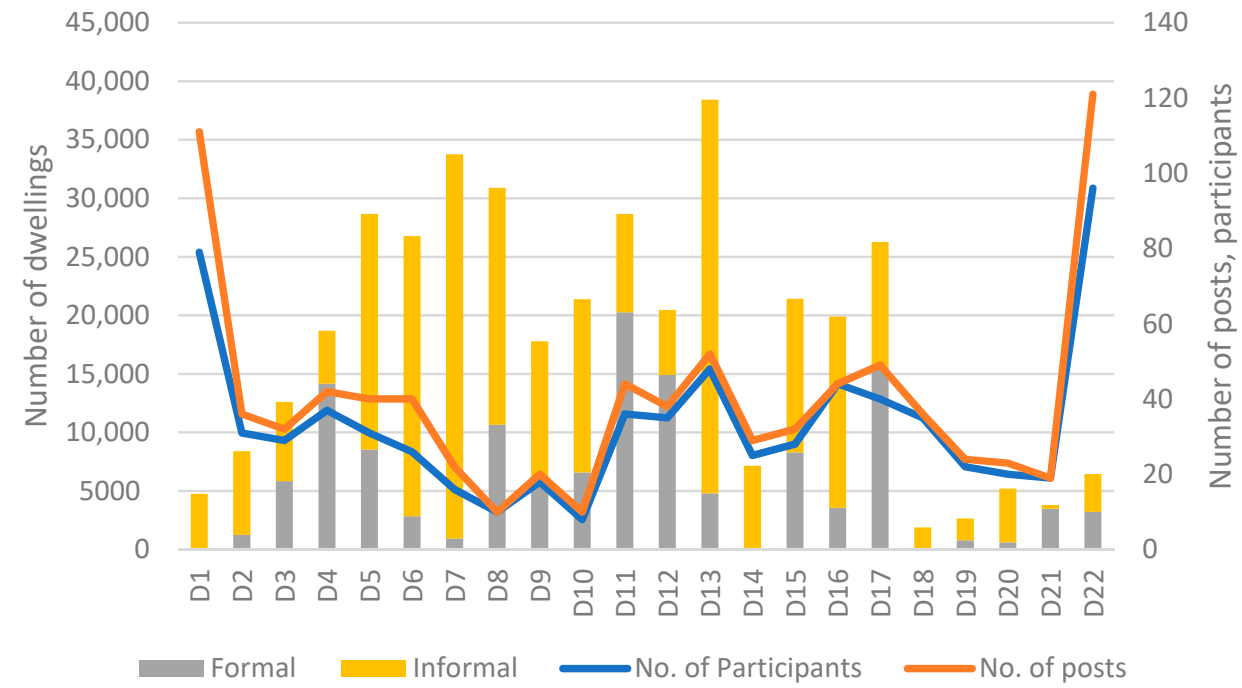

Figure 13. Number of participants and posts from 22 municipal districts dwellings with formal settlements (D4, D11, D12, D17, and D21) and informal settlements (17 other districts).

\subsection{Comparision of Replis in Human and AI Facilitated Messsages Posting}

In order to see the difference between human-facilitated messages $(n=156)$ and AI facilitated messages $(n=215)$ from their part in the process, we checked and analyzed the number of participants replied and label of their IBIS elements for each posting of human-facilitator and AI facilitator. The analysis presents that the case of AI facilitator obtains more Ideas and Cons, while the human facilitated messages are centered around raising Issues and Pros. However, we found no correlation between the reply rate by ratio to human and AI facilitators. The response rate to human facilitator was $63.6 \%$, while the AI facilitator posted facilitated massages received $64.2 \%$ number of replies by participants. About the responses labeling from participants in AI facilitator posting, the extracted IBIS node elements are 0 for Issue; 75 for Idea; 36 for Pros; and 28 for Cons. In addition, the reply post in the human facilitated post are 18 for Issue; 27 for Idea; 19 for Pros; and 36 for Cons. This is mainly due to the facilitation stance and policy. As mentioned before in Section 3.5.2, we use consensus facilitation policy for the proactive agent, where the AI system facilitation is centered around supporting messages to solicit more positive opinions while the human facilitator used their own policy to post their messages. As a result, there is a difference in type of participants response in human and AI facilitators, and the generated input facilitated content of AI leads towards insights which are raised around Ideas and Pros compared to that of a human which is raised around Issues and Cons.

\section{Discussion and Conclusions}

\subsection{Discussion}

Kabul city, for the first time in history, been actively engaged with sustainable urban development goals (SDG-11) through conducting experimental participatory planning at scale. The main goal was to promote citizen-inclusive urban planning and harness the wisdom of crowd for policy making. The collected organized insights will be expressed in Gozar plans, projects and activities in the areas of sustainability. In essence, Kabul city municipal government will translate a vision into Gozar strategic sustainable urban development priorities via a strong participatory planning approach and the joint AI and human-led analysis of the city's main challenges and solutions. In this regard, the proposed approach, the CCDP contributes to implementing this strategic vision by focusing on stimulating participatory development via a securely sustainable participation approach for responding equally to consultation needs of all the population and to "leave no one behind" [122]. 
One strong positive lesson from this initiative (CCDP) is the strong involvement of city (municipality staff, managers, and directors) and citizens. This initiative enables the involvement of all those directly interested in this urban development process of Gozars. Our approach is not necessarily innovative because we have witnessed similar processes in other cities like Nagoya, Japan [81]; however, Kabul city, for example, due to the vast number of involved entities $(+12,000)$, is particularly impressive due to developed and development world partnership as a novel element in participatory planning. In addition, with this implementation, Kabul city became the first amongst LDCs to officially adopt and use an internet-based decision support system based on AI technologies in collaboration with a developed world academia to harness wisdom of crowd for policymaking. As such, this open, deliberative, comprehensive and democratic participatory approach, which includes municipality officials and citizens, could be presented as an innovative example of a transferrable experience, in particular to other Afghan cities like Herat, Mazar, Kandahar and Jalalabad. Indeed, this initiative has already influenced other local Afghan governments, including the cities of Kandahar and Herat as well as the country's central government's ministry of urban planning and land, which have officially expressed their intention to collaborate with us. The key points to CCDP's successful path is the novel partnership and KM strong intention, plan and vision in changing the Kabul city in terms of inclusive urban development management by utilizing emerging civic technologies like D-Agree. Conversely, we forwarded the organized insights and annotated discussion data to $\mathrm{KM}$, thus allowing policymakers the using of simplified and catalogued insights, but not necessarily all insights expected short-medium term impacts in improving the urban development process in Gozars. Although it is not yet possible to make an assessment of the CCDP evaluation, an overview of after the time of horizon of a plan might appear to show that the crowd insights implementation has contributed to inverting the unsatisfactory functions within Gozars or not. In comparisons to traditional participatory planning approaches, the CCDP offers deliberative, democratic and innovative elements. Firstly, the participation is without space constraints, and this allows e-communities to participate if they are interested in urban development processes. Secondly, the discussion ranking system stimulates users' motivation to engage in themed discussion. Thirdly, the discussion facilitation is managed by AI, although AI facilitation is not entirely fair; nevertheless, the AI facilitation is a somewhat fair facilitation compared to bias human facilitation in a country like Afghanistan. In all, it is possible to conclude that both the KM-NITech partnership and CCDP approach present potentially replicable elements of participatory sustainable planning approaches. Overall, it can be argued that the process of CCDP has given an impetus allowing citizens to participate at municipals, supported by extensive collaboration of Kabul city municipal government (Afghanistan) and Nagoya Institute of Technology (Japan).

\subsection{Findings}

This study conducted the first experimental participatory planning on behalf of the Kabul municipal government using a decision-support platform based on AI supportive means to help policymakers collect actual extractions and identify the classified discoursecentric collective of social intelligence for the policymaking of Gozars. We found that Kabul's municipal government's open-call idea that stimulated planning with people may influence the crowd (online communities) into collaborating with the city to find innovative solutions for their common urban problems. The following are some specific findings:

1. An online experiment at Kabul city municipal level offers curious insights from a blended experience that is a mixture of AI technologies and experimental participatory planning in a very challenging context of urban planning in Afghanistan. Our methodology as novel element of develop and developing world partnership is among the earliest adopted participatory e-planning crowdsourcing tools for urban and public policy in Afghanistan. 
2. Our system, artificial facilitation is the earliest adopted automated facilitation tool in municipal government urban development e-planning practices in Afghanistan.

3. Our gamification of online discussion is among the earliest adopted extrinsic motivations in participatory e-planning in Afghanistan.

4. The evaluation of participation and discussion response rate for Theme 1 suggests that most functions are unsatisfactory within Gozars. After the second and third themes were introduced, the participation and discussions evolved to address them. The evaluation of Theme 2 suggests that most of its listed functions were deemed unsatisfactory by the participants. Therefore, the response type as Issue was higher in Theme 2. Thus, most functions are unsatisfactory. This sentiment analysis later aligned with comparison of wakils and residents' opinion in Section 5.2.

5. The responsiveness of the people suggests that the number of quality opinions increased in Theme 2 because in it we specifically addressed discussion questions, and perhaps when the theme specifically addresses an issue, it becomes easier for people to participate and post their opinions. Thus, the more simply we define a problem as a high level issue, the better responses we will collect. This approach might also stimulate argumentation and discussion development in crowdsourcing technologies.

6. In Theme 2, the average daily number of opinions was 87.3 , which exceeds the average daily number of opinions for Themes $1(n=15.7)$ and $3(n=30.9)$. However, the average responsiveness rate was slightly higher in Theme 3 (posts per user $=1.4$ ) than in the other two themes (posts per user 1.1) (Figure 10). In Theme 2, the average IBIS elements from posts (IBISs per post $=2.4$ ) exceeded Theme $1(1.7)$ and Theme $2(1.6)$ (Figure 9).

7. The number of Pros was higher than the Cons in all three discussion themes because the agent facilitated messages encouraged participants to support posted Ideas rather than objecting to them. This is because we adopted a consensus policy for proactive agent and implemented a proactive agent to set the conversational agent's behavior based on consensus policy (mentioned in Section 3.5.2.).

8. The number of participants in the online discussion of 22 municipal districts did not correlate with population or the number of dwellings in a district (Figure 6). However, we assumed that districts with more informal areas are more likely to have unsatisfactory Gozar functions, and therefore, the residents in such areas will be more interested in participating, discussing and sharing their needs and suggestions. This assumption was proven through collecting more suggestion (Ideas and arguments, Pros and Cons) from them compared to the formal area. However, we found no significant difference between the number registrants which came formal and informal settlements areas. Still, the level of participation from communities with lower socioeconomic levels like informal settlements deserve admiration. The support of internet services like installing Wi-Fi zones [123] in informal settlements locations must be provided to them if $\mathrm{KM}$ is willing to harness their wisdom in formalizing their neighborhoods in the future.

9. We found no statistically significant numbers for participation and posts between the formal and informal areas of Kabul city (Figure 13). However, gender and type of response labeling are significant; more ideas and suggestions were received and more women participated from districts with more informal settlements areas.

10. Unlike traditional Gozar gatherings from which women are banned, female participants joined our experiment. We also had many participants from ethnic/religious minorities and achieved meaningful and equal public consultation $[5,17,33]$.

11. We faced no security or health issues. Gathering people for urban dialogues and large-scale social experiments is risky in an unsafe city like Kabul. By using D-Agree, our participants faced no security problems. We also conducted our experiment during the COVID-19 pandemic where lockdowns are one main solution to restrict the spread of the virus. Conducting research using traditional techniques remains complicated during such difficult times [39]. 
12. Unlike conventional in-person town meeting from human facilitation, bias and interest of groups having key position cannot be avoided; AI fair facilitation (automated facilitation) of participatory e-planning and meeting and the real-time discussion extraction and visualization includes all the urban stakeholders and their varied interests and backgrounds to democratically participate, discuss, argue, evaluate and makes a plan that is comprehensive, acceptable, and more easily implementable [2].

\subsection{Comparison of Responses of Residents and Wakils}

We compared the responses that specifically mentioned the satisfactory functions in Theme 2 with those made by wakils from the same list of 18 functions collected during our questionnaire survey [101]. Except for dispute resolution (function no. 5) and community market events (function no. 8), which are listed in Figure 12, the Gozar functions seemed more satisfactory from the viewpoint of the wakils (wakils' viewpoint in response of working functions, $n=16$ ), although only these two functions seemed satisfactory from the citizens' viewpoints (residents' viewpoint in response of working functions, $n=2$ ). We identified a huge contradiction between their opinions and the wakil responses related to the Gozar functions. Next, we investigated whether methodological and time differences impacted the contradictory sample views using a controlled experiment with wakils and citizens using D-Agree. In addition, we reported this difference and discussion annotation files to KM; as a result, the differences affected policy makers to understand the ground reality and KM made a decision to select each wakil through organizing wakil election and call each Gozar resident to vote for their candidate in the future. Previously, KM directly appointed wakils without public consultation.

\subsection{Limitations and Challenges}

Although online-discussion platforms can be a complement tool to effectively collect people's insights and concerns about urban policy and decision-making, our study faced several limitations and challenges that must be addressed in future works.

Literacy, poverty, and limited access to the internet and smartphones are the most conspicuous constraints for online participation in Afghanistan. The adult literacy rate in Afghanistan is 43\% (as of 2018) [124], the per capita GDP is \$502 (as of 2019) [125], and internet access is 13.5\% (as of 2017) [126]. These constraints must be solved by adopting various tools and methods, such as introducing mediation techniques, adding Afghanistan local natural languages like Dari and Pashto to the system, and installing internet spots [123] in Gozar-related gathering halls.

We announced open calls through the Kabul municipality's HP and its Facebook page, without assuming, of course, that all citizens enjoy reliable, consistent internet access. Perhaps due to the high price of normal plans, the majority of Afghan internet users use the Facebook internet plan, which only allows access to Facebook services. If they use such a plan, they cannot connect to our system. This constraint must be tackled by localizing Facebook's internet package with the D-Agree system to allow connections to D-Agree through its Facebook's internet service or implement free Wi-Fi zones and hotspots [123] in 911 Gozars of Kabul city.

We believe that selecting the study area and methodology have many limitations which will be considered in the future. First, we assumed the districts as formal and informal settlements based on the majority rule (districts with most formal and informal settlements), thus, a district with majority formal and informal settlements were considered as formal and informal settlements, respectively. However, in this study we combined all formal and informal settlements within a district and created only 22 virtual discussion space, each for a district. In the future researches, we plan a more controlled settings by selecting areas within a district with formal settlements only and informal settlements and having similar population sizes e.g., experimental participatory with D11 formal settlements and experimental participatory with D11 informal settlements by creating two virtual discussion spaces for D11. Furthermore, as our system currently operate in 
English and Japanese language, we ignored the IBIS elements written in local languages (Farsi Dari and Pashto). This is because our system document summarization system and node and link extractions [110] are based on English and Japanese languages. In the future researches, we plan to train the node and link extractions by collecting dataset of discussions conducted in Afghanistan two official languages (Farsi Dari and Pashto) and adding them to the system.

\subsection{Conclusions and Future Perspectives}

This paper proposed a novel approach called crowd-based communicative and deliberative e-planning (CCDP). We signed an agreement between academia (NITech) and a municipal government (KM) by introducing an AI-enabled, decision support system that can harness participation in urban policymaking in Kabul city. In particular, Kabul city conducted a large-scale discussion with our system for the strategic development of Gozar-related planning.

For data collection, our system used a visualization and extraction method to support e-participation by gathering opinions at scale about the neighborhood functions of urban units in Kabul city. A conversational agent gathered, analyzed, and facilitated the discussions. We then analyzed the contents of the machine-led, extracted opinions that were collected using qualitative content analysis methods to shape policymaking for urban units. The discussion insights revealed that an e-participatory supportive tool encouraged effective participation based on gender equality and can promote communicative planning in Afghanistan. This step makes opinion collection more reliable and increases the transparency and legitimacy of the decision-making and policymaking processes. After comparing part of the submitted opinions on the satisfactory functions in Theme 2 with those collected from the wakil responses on satisfactory functions, we found that most Gozar functions are seen as unsatisfactory by the citizens. Another main contribution of this study is that our system is raising solutions for social issues, and many people outlined the reasons and suggested solutions for fixing them. Thus, our system led discussions toward outcome-based consensus building and achieved a consensus not only on issues but also on ideas at the collective level. These valuable, annotated, and classified insights help policymakers make appropriate and efficient decisions related to urban planning.

Venues also exist for further studies and experiments. Our next steps are (1) to train the node and link extractions by collecting dataset of discussions conducted in Afghanistan two official languages (Farsi Dari and Pashto) and adding them to the system, and (2) to conduct a cross-person (residents-wakil) control experiment using open-ended online questionnaires, Facebook, and D-Agree as discussion tools for themed discussions, followed by analysis contents and discourse structure to statistically identify the evidence raised by our system around solutions. Our propositions/hypotheses are that Afghan citizens will submit opinions around raising issues (issues and cons) using Facebook or open-ended online questionnaires. The opinions of citizens will focus on raising solutions (ideas and pros) using our system. We will investigate how such methodological differences impacted the sample views with sociocultural backgrounds using open-ended questionnaires, Facebook, and D-Agree within a more controlled setup. Furthermore, we are working on a GAT method [112] implementation for our system to improve the accuracy of the node and link extractions [105].

The second step will extend our research to include more Afghan cities like Kandahar and Herat and upgrade the collaboration level from local to central governments to stimulate participatory e-planning in the country. Our final direction will reframe the system as a participatory-planning social platform, which can maintain a social network, where discussions should be about urban-related planning to offer innovative solutions for improving the city in line with the United Nations' sustainable development goals (SDG-11 13).

Author Contributions: Conceptualization, J.H. and S.S.; methodology, J.H., S.S. and T.I.; software, J.H. and T.I.; validation, J.H. and S.S.; formal analysis, J.H., S.S., P.R. and T.I.; investigation, J.H., 
S.S., P.R., and T.I.; resources, J.H., S.S. and T.I.; data curation, J.H. and S.S.; writing-original draft preparation, J.H. and S.S.; writing-review and editing, J.H. and S.S.; visualization, J.H., S.S. and T.I.; supervision, T.I.; project administration, J.H. and S.S.; funding acquisition, T.I. All authors have read and agreed to the published version of the manuscript.

Funding: This research and APC were funded by the Japan Science and Technology Agency JST CREST, grant number JPMJCR20D1, and the JST AIP Challenge Program, Japan.

Institutional Review Board Statement: This study was reviewed by the Nagoya Institute of Technology and Afghanistan's ministry of public health institutional review board (IRB code No.E.1220.0254) and, due to lack of individual human subjects, found to be exempt.

Informed Consent Statement: Informed consent was obtained from all subjects involved in the study.

Data Availability Statement: The data is available upon request at https:/ /www.d-agree.com/ (accessed date 12 May 2020).

Acknowledgments: The authors express their gratitude and appreciation to Kabul municipality and all the people who participated in this study.

Conflicts of Interest: The authors declare no conflict of interest. The funders had no role in the design of the study; in the collection, analyses, or interpretation of data; in the writing of the manuscript, or in the decision to publish the results.

\section{References}

1. Innes, J.E. Information in Communicative Planning. J. Am. Plan. Assoc. 1998, 64, 52-63. [CrossRef]

2. Burby, R.J. Making Plans that matter: Citizen Involvement and Government Action. J. Am. Plan. Assoc. 2003, 69, 33-49. [CrossRef]

3. Haltofova, B. Using Crowdsource to Support Civic Engagement in Strategic Urban Development Planning: A Case Study of Ostravea, Czech Republic. J. Compet. 2018, 10, 85-103.

4. Arnstein, S.R. A Ladder of Citizen Participation. J. Am. Inst. Plan. 1969, 35, 216-224. [CrossRef]

5. Rizzi, P.; Porebska, A. Towards a Revise Framework for Participatory Planning in the Context of Risk. Sustainability 2020, $12,5539$. [CrossRef]

6. Boukharis, I.; Ayachi, R.; Elouedi, Z.; Mellouli, S.; Amor, N.B. Decision Model for Policy Maker in the Context of Citizens Engagement: Application on Participatory Budgeting. Soc. Sci. Comp. Rev. 2016, 34, 740-756. [CrossRef]

7. Kumar, A.K.S. Analysis and Evaluation of Public Policy: Some Reflection. J. Dev. Policy Pract. 2016, 1, 117-120. [CrossRef]

8. Kochskamper, E.; Challies, E.; Newig, J.; Jager, N.W. Participation for Effective Environmental Governance? Evidence from Water Framework Directive Implementation in Germany, Spain and the United Kingdom. J. Environ. Manag. 2016, 181, 737-748. [CrossRef]

9. Hassan, G.F.; Hefnawi, A.E.; Refaie, M.E. Efficiency of Participation in Planning. Alex. Eng. J. 2011, 50, 203-211. [CrossRef]

10. Wang, A.; Hu, Y.; Li, L.; Liu, B. Group Decision Making Model of Urban Renewal based on Sustainable Development: Public Participation Perspective. Procedia Eng. 2016, 145, 1509-1517. [CrossRef]

11. Macintosh, A.; Whyte, A. Towards an Evaluation Framework for eParticipation. Trans. Gov. People Proc. Policy 2008, 2, 16-30. [CrossRef]

12. Haqbeen, J.; Ito, T.; Hadfi, R.; Sahab, Z.; Sahab, S.; Amiryar, R.; Nishida, T. Usage \& Application of AI-based Discussion Facilitation System for Urban Renewal in Selected Districts of Kabul City: Afghanistan Experimental View. In Proceedings of the 34th Annual Conference of the Japanese Society for Artificial Intelligence, Kumamoto, Japan, 9-12 June 2020; pp. 1-4.

13. Lawrence, J.; Reed, C. Mining Argumentative Structure from Natural Language Text using Automatically Generated PremiseConclusion Topic Models. In The 4th Workshop on Argument Mining; Association for Computational Linguistics Publisher: Copenhagen, Denmark, 2017; pp. 39-48.

14. Brail, R.; Klosterman, R. Planning Support Systems: A New perspective on Computer-aided Planning. In Planning Support Systems: Integrating Geographic Information Systems, Models and Visualization Tools; ESRI-Press: Redlands, CA, USA, 2001; pp. 1-24.

15. Forster, J. The Deliberative Practitioner: Encouraging Participatory Planning Processes, 1st ed.; The MIT Press: Cambridge, MA, USA, 1999; pp. 1-15.

16. Mark, R.S. Internet BSSs: A Guided Tour, 1st ed.; Manning Publication: Shelter Island, NY, USA, 1996; pp. 1-16.

17. Saad-Sulonen, J. Combining Participations. Expanding the Locus of Participatory e-Planning by Combining Participatory Approaches in the Design of Digital Technology and in Urban Planning. Doctoral Dissertation, Aalto University, Espo, Finland, 2014.

18. Beath, A.; Fotini, C.; Ruben, E. Empowering Women: Evidence from a Field Experiment in Afghanistan; Policy Research Working Paper, No. 6269; World Bank: Washington, DC, USA, 2012; pp. 1-39. 
19. UNAMA. Afghanistan Annual Report on Protection of Civilian in Armed Conflict. 2019. Available online: https://unama. unmissions.org/sites/default/files/afghanistan_protection_of_civilians_annual_report_2019_-_22_february.pdf (accessed on 24 November 2020).

20. Richardson, T.; Dusik, J.; Jindrova, P. Parallel Public Participation: An Answer to Inertia in Decision-making. Environ. Impact. Assess. Rev. 1998, 18, 201-216. [CrossRef]

21. Kengne, C.N.; Evouna, S.E.M.; Bitondo, D. Public Hearing in Environmental and Social Impact Assessment for Energy Sector Projects in Cameroon. Impact Assess. Proj. Apprais. 2013, 31, 64-73. [CrossRef]

22. Aminzadeh, B.; Sani, R.R. Evaluation of Public Participation in Tarhhaye Manazar Shahzfri (urban landscape plans). Fin. Ar. Archit. Urban Plan. 2012, 17, 29-40.

23. Macintosh, A. Characterizing e-Participation in Policy-making. In Proceedings of the 37th Annual Hawaii International Conference on System Sciences, Big Island, HI, USA, 5-8 January 2004; pp. 1-10.

24. Ito, T.; Ito, T.; Hideshima, E. COLLAGREE: A Facilitator-mediated Largescale Consensus Support System. In Proceedings of the 2nd ACM Collective Intelligence, Warsaw, Poland, 11-14 August 2014; MIT: Cambridge, MA, USA, $2014 ;$ pp. 10-12.

25. Imi, Y.; Ito, T.; Ito, T.; Hideshima, E. A Development of Consensus Support System COLLAGREE and a Pilot Study towards Internet-based Town Meeting in Nagoya. In Proceedings of the 28th Annual Conference of the Japanese Society for Artificial Intelligence, Matsuyama, Japan, 12-15 May 2014; The Japanese Society for Artificial Intelligence: Tokyo, Japan, 2014.

26. Silva, C.N. Open-Source Urban Governance: Citizen e-Participation in Urban Governance; IGI Global Publisher: Pennsylvania, PA, USA, 2013; pp. 1-18.

27. Silva, C.N. Citizen e-Participation in Urban Governance: Crowdsourcing and Collaborative Creativity, 1st ed.; IGI Global Publisher: Pennsylvania, PA, USA, 2013; pp. 35-48.

28. Albercht, S.; Kohlrausch, N.; Kubicek, H.; Lippa, B.; Marker, O.; Trenel, M.; Wiedwald, C. eParticipation Electronic Participation of Citizens and the Business Community in eGoverment; Insitut fur Infromationsmanagement: Brement, Germany, 2008 ; pp. 1-27.

29. Evans-Cowley, J.; Hollander, J. The New Generation of Public Participation: Internet-based Participation Tools. Plan. Pract. Res. 2010, 5, 397-408. [CrossRef]

30. Tavanapour, N.; Poser, M.; Bittner, E.A.C. Supporting the Idea Generation Process in Citizen Participation-toward an Interactive System with a Conversational Agent as Facilitator. In Proceedings of the 27th European Conference on Information Systems (ECIS), Stockholm \& Uppsala, Sweden, 8-14 June 2019; pp. 1-17.

31. Evans-Cowley, J. Planning in the Age of Facebook. GeoJournal 2010, 75, 407-420. [CrossRef]

32. Harris, N. Collaborative Planning: From Theoretical Foundations to Practice Forms. In Planning Futures: New Directions for Planning Theory, 1st ed.; Allmendinger, P., Tewdwr-Jones, M., Eds.; Routledge: London, UK, 2002; pp. $23-35$.

33. Ito, T.; Shibita, D.; Suzaki, S.; Yamaguchi, N.; Nishida, T.; Hiraishi, K.; Yoshino, K. Agent that Facilitates Crowd Discussion. In Proceedings of the 7th ACM Collective Intelligence, Pittsburgh, PA, USA, 13-14 June 2019; Association for Computing Machinery: New York, NY, USA, 2019.

34. Sengoku, A.; Ito, T.; Takahashi, K.; Shiramatsu, S.; Ito, T.; Hideshima, E.; Fujita, K. Discussion Tree for Managing Large-scale Internet-based Discussions. In Proceedings of the 4th ACM Collective Intelligence; ACM Collective Intelligence Conference Series; ACM: New York, NY, USA, 2016.

35. Takahashi, K.; Ito, T.; Ito, T.; Hideshima, E.; Shiramatsu, S.; Sengoku, A.; Fujita, K. Incentive Mechanism Based on Quality of Opinion for Large-Scale Discussion Support. In Proceedings of the 4th ACM Collective Intelligence; ACM Collective Intelligence Conference Series; ACM: New York, NY, USA, 2016.

36. Dia, W.; Wang, Y.; Jin, Q.; Ma, J. An Integrated Incentive Framework for Mobile Crowdsourced Sensing. Tsinghua Sci. Technol. 2016, 21, 146-156.

37. Stab, C.; Guevych, I. Parsing argumentation structures in persuasive essays. Comput. Linguest. 2017, 43, 619-659. [CrossRef]

38. Simpson, D. Use of Web Technologies by U.S. Planning Agencies: Results from a National Benchmarking Survey. In U.S. Municipal Year Book 2005; ICMA Press: Washington, DC, USA, 2005; pp. 22-26.

39. Haqbeen, J.; Ito, T.; Sahab, S.; Sato, T.; Okuhara, S.; Hofiani, M. Insights from a Large-scale Discussion on COVID-19 in Collective Intelligence. In Proceedings of the 19th IEEE/WIC/ ACM International Conference on Web Intelligent and Agent Technology, ACM, Virtual Conference, Melbourne, Australia, 14-17 December 2020.

40. Brabham, D.C. Crowdsourcing as a Model for Problem Solving: An Introduction and Cases. Convergence 2008, 14, 75-90. [CrossRef]

41. Ayeni, B. The Design of Spatial Decision Support Systems in Urban and Regional Planning. In Decision Support Systems in Urban Planning Book, 1st ed.; Timmermans, H., Ed.; Routledge: London, UK, 1998; pp. 1-32.

42. Moody, R. Assessing the Role of GIS in e-Government: A tale of e-Participation in two Cities. In Proceedings of the 6th International Conference on Electronic Government, Regensburg, Germany, 3-7 September 2007; Springer: Berlin, Germany, 2007; pp. 354-365.

43. Sieber, R. Participatory Geoweb: A research Agenda. In Proceedings of the Spatial Knowledge and Information Canada Conference, Vancouver, BC, Canada, 10-12 June 2008; pp. 59-60.

44. Fischer, F.; Forester, J. The Argumentative Turn in Policy Analysis and Planning, 1st ed.; Duke University Press: Durham, UK, 1993; pp. 1-21. 
45. Malone, T.W.; Klein, M. Harnessing collective intelligence to address global climate change. Innov. Technol. Gov. Glob. 2007, 2, 15-26. [CrossRef]

46. Howe, J. The rise of crowdsourcing. Wired Mag. 2006, 14, 1-4.

47. Woolley, A.W. Responses to Adversarial Situations and Collective Intelligence. J. Org. Behav. 2011, 32, 978-983. [CrossRef]

48. Wellman, B.; Haythornthwaite, C. The Internet in Everyday Life, 1st ed.; Wiley-Blackwell: New Jersey, USA, 2002; pp. 45-58.

49. Yigitcanlar, T. Is Australia Ready to Move Planning to Online Mode? Aust. Plan. 2005, 42, 42-51. [CrossRef]

50. Yigitcanlar, T. Australian Local Governments Practice and Prospects with Online Planning. URISA J. $2006,18,7-17$.

51. Gordon, G.L. Strategic Planning for Local Government, 2nd ed.; ICMA Publishing: Washington, DC, USA, 2013 ; pp. 38-54.

52. Medeiros, E.; van der Zwet, A. Sustainable and Integrated Urban Planning and Governance in Metropolitan and Medium-Sized Cities. Sustainability 2020, 12, 5976. [CrossRef]

53. Wamsler, C. Evaluation on Crowdsourcing Research: Current Status and Future Direction. Inf. Syst. Front. 2016, 16, 417-434.

54. Brabham, D.C. Using Crowdsourcing in Government, 1st ed.; IBIM Center for the Business of Government: Washington, DC, USA, 2013; pp. 7-27.

55. Hiltz, S.R.; Kerr, E.B. Studies of Computer Mediated Communications Systems: A Synthesis of the Findings; Computerized Conferencing and Communications Center Reports; New Jersey Institute of Technology: Newark, NJ, USA, 1982; pp. 1-18.

56. Johson-Lenz, P.; Johson-Lenz, T. Post-mechanistic Grouware Primitives: Rhythms, Boundries and Containers. Int. J. Man Mach. Stud. 1991, 34, 395-417. [CrossRef]

57. Palme, J. History of the KOM Computer Conferencing System; Stockholm University: Stockholm, Sweden, 2015.

58. Shirky, C. Here Comes Everybody: The Power of Organizing without Organizations, 1st ed.; Penguin Publishing Group: London, UK, 2008; pp. 14-36.

59. Hossain, M.; Kauranen, I. Crowdsourcing: A Comprehensive Literature Review. Strateg. Outsourc. Int. J. 2015, 8, 2-22. [CrossRef]

60. Hossain, M. Users' Motivation to Participate in Online Crowdsourcing Platforms. In Proceedings of the International Conference on Innovation Management and Technology Research, Malacca, Malaysia, 21-22 May 2012; pp. 310-315.

61. Malone, T.W. The Future of Work: How the New Order of Busines will Share Your Organization, Your Management Style and Your Life, 1st ed.; Harvard Business School Press: Boston, MA, USA, 2004; pp. 1-24.

62. Malone, T.W.; Bernstein, M.S. Handbook of Collective Intelligence, 1st ed.; MIT Press: Cambridge, MA, USA, 2015 ; pp. 83-98.

63. Brabham, D.C. Crowdsourcing, 1st ed.; MIT Press: Cambridge, MA, USA, 2013; pp. 12-23.

64. Brabham, D.C. Crowdsourcing the Public Participation Process for Planning Projects. Plan. Theory 2009, 8, 242-262. [CrossRef]

65. Schenk, E.; Guittard, C. Towards a Characterization of Crowdsourcing Practices. J. Innov. Econ. Manag. 2011, 1, 93-107. [CrossRef]

66. Hudson-Smith, A.; Evans, S.; Batty, M.; Batty, S. Online Participation: The Woodberry down Experiment. Center for Advanced Spatial Analysis (CASA); Working Papers Series, Paper 60; University College London (UCL): London, UK, 2002; pp. 1-13.

67. Shen, Z.; Kawazawa, M.; Kishimoto, K. Study on the Development of an Online Design Collaboration Dystem for Public Participation-A Case Study of Public Park Planning and Design. In Proceedings of the 6th International Conference on Design and Decision Support Systems in Architecture and Urban Planning, Ellecom, The Netherlands, 7-10 July 2002; pp. $224-239$.

68. Moon, T. On-line Participation for the Collaborative Planning. In Proceedings of the 4th International Symposium on City Planning and Environment Management in Asian Countries, AURG Asian Urban Research Group, Seoul, Korea, 11-14 January 2004; pp. 219-232.

69. Mahendra, W.; Pratiwi, M.; Prawesti, R. Citizens' Aspirations and Complaints Online System (LAPOR) in Indonesia: Making Citizens Happy. In Proceedings of the World Conferece for Public Administration, Daegu, Korea, 26 June 2014.

70. Swezey, R.M.E.; Sano, H.; Hirata, N.; Shiramatsu, S.; Ozono, T.; Shintani, T. An e-Participation Support System for Regional Communities based on Linked Open Data, Classification and Clustering. In Proceedings of the IEEE 11th International Conference on Cognitive Informatics and Cognitive Computing, Kyoto, Japan, 22-24 August 2012; pp. 211-218.

71. Mahmoud, H.; Arima, T. A Web-based Public Participation System that Supports Decision Making. J. Asian Arch. Build. Eng. 2011, 10, 77-84. [CrossRef]

72. Ito, T. Towards Agent-based Large-scale Decision Support System: The Effect of Facilitation. In Proceedings of the 51st Hawaii International Conference on System Science, Big Island, HI, USA, 2-6 January 2018; AIS eLibrary: Big Island, HI, USA, 2018; pp. 351-360.

73. Sowmya, J.; Pyarali, H.S. The Effective use of Crowdsourcing in e-Governance. In Proceedings of the 13th International Conference on Electronic Business, Taipei, Taiwan, 8-12 December 2014; Nanyang Technological University: Singapore, $2014 ;$ pp. $217-231$.

74. Ito, T.; Hadfi, R.; Haqbeen, J.; Suzuki, S.; Sakai, A.; Kawamura, N.; Yamaguchi, N. Agent-Based Crowd Discussion Support System and Its Societal Experiments. In Advances in Practical Applications of Agents, Multi-Agent Systems, and Trustworthiness, 1st ed.; Demazeau, Y., Holvoet, T., Corchado, J., Costantini, S., Eds.; Springer: L'Aquila, Italy, 2020; pp. 430-433.

75. Haqbeen, J.; Ito, T.; Sahab, S. AI-based mediation improves opinion solicitation in a large-scale online discussion: Experimental evidence from Kabul Municipality. In Proceedings of the 29th International Joint Conference on Artificial Intelligence (IJCAI) Workshop on AI for Social Good, Yokohama, Japan, 7-15 January 2021; Center for Research on Computation and Society, Harvard University: Cambridge, MA, USA, 2021.

76. Haqbeen, J.; Ito, T.; Hadfi, R.; Nishida, T.; Sahab, Z.; Sahab, S.; Roghaml, S.; Amiryar, R. Promoting Discussion with AI-based Facilitation: Urban Dialogue with Kabul City. In Proceedings of the 8th ACM Collective Intelligence, ACM Collective Intelligence Conference Series, Boston (Virtual Conference), South Padre Island, TX, USA, 18 June 2020. 
77. Layne, K.; Lee, J. Developing Fully Functional e-Government: A Four Stage Model. Gov. Inf. Q. 2001, 18, 122-136. [CrossRef]

78. Kawase, S.; Ito, T.; Otsuka, T.; Sengoku, A.; Shiramatsu, S.; Matsu, T.; Oishi, T.; Fujita, R.; Fukuta, N.; Fujita, K. Cyber-physical Hybrid Environment Using a Largescale Discussion System Enhances Audiences' Participation and Satisfaction in the Panel Discussion. IEICE Trans. Inf. Syst. 2018, 101, 847-855. [CrossRef]

79. Ito, T.; Suzuki, S.; Yamaguchi, N.; Nishida, T.; Hiraishi, K.; Yoshino, K. Towards smarter democracy: An agent-based large-scale discussion support system. In Proceedings of the 28th International Joint Conference on Artificial Intelligence (IJCAI) Workshop on AI for Social Good, Macao, China, 11-12 August 2019.

80. Ito, T.; Ostuka, T.; Kawasa, S.; Sengoku, A.; Shiramatsu, S.; Ito, T.; Hideshima, E.; Matsuo, T.; Oishi, T.; Fujita, R.; et al. Experimental Results on Large-scale Cyber-physical Hybrid Discussion Support. Int. J. Crowd Sci. 2017, 1, 26-38. [CrossRef]

81. Imi, Y.; Ito, T.; Ito, T.; Hideshima, E. A Large-scale Consensus Support System called COLLAgREE based on Online Facilitation Functions-A Real-world Application for Nagoya Next Generation Total City Planning. Inf. Process. Soc. Jpn. J. 2015, 56, 1996-2010.

82. Insua, D.R.; Kersten, G.E.; Rios, J.; Grima, C. Towards Decision Support for Participatory Democracy. Inf. Syst. e-Bus. Manag 2008, 6, 161-191. [CrossRef]

83. Rabinowitz, P. Participatory Approaches to Planning Community Interventions. The Community Tool Box. 2013. Available online: http:/ / ctb.ku.edu/en/tablecontents/sub_section_main_1143.aspx (accessed on 4 January 2021).

84. Garcia, A.C.B.; Vivacqua, A.S.; Tavares, T.C. Enabling Crowd Participation in Governmental Decision-making. J. Univ. Comput. Sci. 2011, 17, 1931-1950.

85. Casy, C.; Li, J. Web 2.0 Technologies and Authentic Public Participation: Engaging Citizens in Decision Making Process, In Citizen 2.0: Public and Governmental Interaction through Web 2.0 Technologies, 1st ed.; Kloby, K., D'Agostino, M.J., Eds.; IGI Global: Pennsylvania, PA, USA, 2012; pp. 1-27.

86. Sundstrom, L.M. i-Government: Interactive Government Enabling Civic Engagement and a New Volunteerism. In Citizen 2.0: Public and Governmental Interaction through Web 2.0 Technologies, 1st ed.; Kloby, K., D'Agostino, M.J., Eds.; IGI Global: Pennsylvania, PA, USA, 2012; pp. 297-308.

87. Antiroiko, A.V. Urban Planning 2.0. Int. J. e-Plan. Res. 2012, 1, 16-30.

88. Rowe, G.; Frewer, L.J. Public Participation Methods: A Framework for Evaluation. Sci. Technol. Hum. Values 2000, 25, 3-29. [CrossRef]

89. Lehdonvirta, V.; Bright, J. Crowdsourcing for Public Policy and Government. Policy Internet 2015, 7, 263-267. [CrossRef]

90. Smith, G. Democratic Innovations: Designing Institutions for Citizen Participation; Cambridge University Press: Cambridge, UK, 2009; pp. 142-161.

91. Aitmaurto, T.; Landemore, H.; Saldivar, G.J. Unmasking the Crowd: Participants' Motivation Factors, Expectations, and Profile in a Crowdsourced Law Reform. Inf. Commun. Soc. 2017, 20, 1239-1260. [CrossRef]

92. Zuccon, G.; Leelanupab, T.; Whiting, S.; Yilmaz, E.; Jose, J.M.; Azzopardi, L. Crowdsourcing Interactions: Using Crowdsourcing for Evaluating Interaction information Retrieval Systems. Inf. Retr. 2013, 16, 267-305. [CrossRef]

93. Ryo, S.; Yetano, A. Crowdsourcing as a Tool for e-Participation: Two Experiences regarding $\mathrm{CO}_{2}$ Emission at Municipal Level. Electron. Commer. Res. 2015, 15, 323-348. [CrossRef]

94. Schweitzer, F.; Buchinger, W.; Gassmann, O.; Obrist, M. Crowdsourcing: Leveraging Innovation through Online Idea Competitions. IEEE Eng. Manag. Rev. 2013, 41, 24-32. [CrossRef]

95. Spiliotopoulou, L.; Charalabidis, Y.; Loukis, N.E.; Diamantopoulou, V. A Framework for Advanced Social Media Exploitation in Government for Crowdsourcing. Transform. Gov. People Process Policy 2014, 8, 545-564. [CrossRef]

96. Koch, G.; Fuller, J.; Brunswicker, S. Online Crowdsourcing in the Public Sector: How to Design Open Government Platforms. In Online Communities and Social Computing; Ozok, A.A., Zaphiris, P., Eds.; Lecture Notes in Computer Science; Springer: Berlin/Heidelberg, Germany, 2009; Volume 6778, pp. 203-212.

97. Collm, A.; Schedler, K. Managing Crowd Innovation in Public Administration. Int. Public Manag. Rev. 2012, 13, 1-18.

98. Tapscott, D.; Williams, A.D.; Herman, D. Government 2.0: Transforming Government and Governance for the Twenty-First Century. New Paradigm. 2008. Available online: https://www.academia.edu/402138/Government_2_0_Transforming_ Government_and_Governance_for_the_Twenty_First_Century (accessed on 4 January 2021).

99. Thompson, S.K. Sampling, 3rd ed.; John Wiley \& Sons: Hoboken, NJ, USA, 2012; pp. 171-175.

100. Baltes, S.; Ralph, P. Sampling in Software Engineering Research: A Critical Review and Guidelines. arXiv 2020, arXiv:2002.07764.

101. Sahab, S.; Kaneda, T. A Study on Neighborhood Functions of 'Gozars' in Kabul, Afghanistan. AIJ Trans. J. Arch. Plan. 2015, 80, 2253-2260. [CrossRef]

102. NISA. Estimated Population of Afghanistan 2020-2021. Available online: https://nsia.gov.af/library (accessed on 24 November 2020).

103. Sahab, S.; Meziani, R.; Kaneda, T. A Visionary Study on Urban Neighborhood Models in Kabul City based on Actual Surveys. In Proceedings of the 19th International conference on Urban Planning, Regional Development and Information Society, Vienna, Austria, 21-23 May 2014; Competence Center for Uaban and Regional Planning: Vienna, Austria, 2014; pp. 45-54.

104. Sahab, S.; Kaneda, T. A Study on the Lifestyles and Daily Activities of Informal Settlers in Inner Kabul City. In Proceedings of the 21st International conference on Urban Planning, Regional Development and Information Society, Hamburg, Germany, 22-24 June 2016; Competence Center for Uaban and Regional Planning: Vienna, Austria, 2016; pp. 47-55. 
105. Suzuki, S.; Yamaguchi, N.; Nishida, T.; Moustafa, A.; Shibata, D.; Yoshino, K.; Hiraishi, K.; Ito, T. Extraction of Online Discussion Structures for Automated Facilitation Agent. In Proceedings of the 33th Annual Conference of the Japanese Society for Artificial Intelligence, Nigata, Japan, 4-7 June 2019; pp. 150-161.

106. Frey, K.; Luthje, C.; Haag, S. Whom Should Firms Attract to Open Innovation Platforms? The role of knowledge diversity and motivation. Long Range Plan. 2011, 44, 397-420. [CrossRef]

107. Kuz, W.; Kunz, W.; Rittel, H.W. Issues as Elements of Information Systems. Tech. Rep. 1970. Available online: http:// citeseerx.ist. psu.edu/viewdoc/download?doi=10.1.1.134.1741\&rep=rep1\&type=pdf (accessed on 24 November 2020).

108. Liu, Y. Fine-tune BERT for Extractive Summarization. arXiv 2019, arXiv:1903.10318.

109. Bojanowski, P.; Grave, E.; Joulin, A.; Mikolov, T. Enriching Word Vectors with Subword Information. Trans. Assoc. Comput. Linguist. 2017, 5, 135-146. [CrossRef]

110. Schuster, M.; Kuldip, K.P. Bidirectional Recurrent Neural Networks. IEEE Trans. Signal Process. 1997, 45, 2673-2681. [CrossRef]

111. Stone, M. Cross-validatory Choice and Assessment of Statistical Predictions. J. R. Stat. Soc. 1974, 36, 111-133. [CrossRef]

112. Suzuki, S.; Ito, T.; Moustafa, A.; Hadfi, R. A Node Classification Approach for Dynamically Extracting the Structures of Online Discussions. In Proceedings of the 34th Annual Conference of the Japanese Society for Artificial Intelligence, Kumamoto, Japan, 9-12 June 2020; pp. 1-4.

113. Veličković, P.; Cucurull, G.; Casanova, A.; Romero, A.; Lio, P.; Bengio, Y. Graph Attention Networks. arXiv 2017, arXiv:1710.10903.

114. Amazon. Amazon Web Services in Action. 2015. Available online: https://www.manning.com/books/amazon-web-services-inaction (accessed on 24 November 2020).

115. French, M.; Popal, A.; Rahimi, H.; Popure, S.; Turkstra, J. Institutionalizing Participatory Slum Upgrading: A Case Study of Urban Co-production from Afghanistan, 2002-2016. Environ. Urban. 2018, 31, 209-230. [CrossRef]

116. StataCorp. Stata/Se 16.1. (Registered Academic Licensed). 2020. Available online: https://www.stata.com/new-in-stata/ (accessed on 24 November 2020).

117. Provalis Research. WordStat 8. (Registered academic licensed). 2018. Available online: https://provalisresearch.com/products/ content-analysis-software/wordstat-whats-new / (accessed on 24 November 2020).

118. Nazir, H.; Kita, M. Specifying Characteristics of Informal Settlements by Comparing four Areas from the Aspects of Houses, Land Tenure and Social Factors in Kabul, Afghanistan. J. Archit. Plan. 2016, 81, 2197-2206. [CrossRef]

119. The World Bank. Why and How Should Kabul Upgrade Its Informal Settlements? 2005. Available online: http:/ / documents1 .worldbank.org/curated/ar/684031467995795185/pdf/370840ENGLISH01licy1Note1201PUBLIC1.pdf (accessed on 24 November 2020).

120. Hassan, G.F. Regeneration as an Approach for the Development of Informal Settlements in Cairo Metropolitan. Alex. Eng. J. 2012, 51, 229-239. [CrossRef]

121. Japan International Cooperation Agency. Draft Kabul City Master Plan. 2011. Available online: https://openjicareport.jica.go.jp/ pdf/12058566_01.pdf (accessed on 24 November 2020).

122. United Nation. UN Sustainable Development Group. Available online: https://unsdg.un.org/2030-agenda/universal-values/ leave-no-one-behind (accessed on 24 November 2020).

123. Vermont Digital Economy Project. Planning and Implementing a Wi-Fi Zone for Your Town. 2011. Available online: https: //www.vtrural.org/programs/digital-economy/services/wifi/toolkit (accessed on 24 November 2020).

124. World Bank. World Development Indicators. Literacy Rate, Adult Total (\% of People Ages 15 and above). Available online: https: / / data.worldbank.org/indicator/SE.ADT.LITR.ZS (accessed on 24 November 2020).

125. World Bank. World Development Indicators. GDP per Capita (Current US\$). Available online: https://data.worldbank.org/ indicator/NY.GDP.PCAP.CD (accessed on 24 November 2020).

126. World Bank. World Development Indicators. Individuals Using Internet (\% of Population). Available online: https://data. worldbank.org/indicator/IT.NET.USER.ZS (accessed on 24 November 2020). 